\title{
Kinetics of Oxygen Exchange, Photosynthesis, and Respiration in Rivers Determined From Time-Delayed Correlations Between Sunlight and Dissolved Oxygen
}

\author{
By J. M. Schurr and J. Ruchti \\ Department of Chemistry, University of Washington, Seattle, Washington (USA) \\ and \\ Eidgenössische Anstalt für Wasserversorgung, Abwasserreinigung \\ und Gewässerschutz (EAWAG), Dübendorf (Switzerland)
}

Manuscript received 8 January 1975

\begin{abstract}
The application of both a simple rate equation and a novel cross-correlation computational technique to dissolved oxygen records has enabled a determination of the oxygen exchange constant, photosynthesis rate, and rate of respiration for several Swiss rivers. An extension of this method to determine total carbonate dynamics from continuous $\mathrm{pH}$ records is also described.

Results for the Aare at Bern (March, 1974) are : $0.38 \mathrm{~h}^{-1}$ for oxygen exchange constant, $0.6-0.8$ $\mathrm{mg} /(1 \mathrm{~h})$ for respiration rate, and $0.28 \mathrm{mg} /(1 \mathrm{~h})$ for mean photosynthesis rate. Moreover the exchange rate for dissolved (but not hydrated or ionized) $\mathrm{CO}_{2}$ was 0.91 times that for oxygen, and the ratio of $\mathrm{O}_{2}$ molecules released to $\mathrm{CO}_{2}$ molecules consumed during photosynthesis was 1.2 .
\end{abstract}

\section{Introduction}

Ever since the classic work of Streeter and Phelps [1] in 1925 it has been recognized that the rate of oxygen exchange between a stream and the atmosphere, often referred to as the reaeration rate, was one of the critical parameters in the selfpurification process. The problem has been to obtain a reliable estimate of this oxygen exchange rate for a flowing body of water. Previously proposed methods for estimating the exchange rate may conveniently be classified as either direct, or indirect.

The indirect, or model-building, methods consist basically of guessing the equations-of-motion governing the dynamical changes of the dissolved oxygen in the river, and the subsequent adjustment of parameters appearing in the equations-ofmotion until an optimum fit of the predicted time-evolution of the dissolved oxygen to the experimentally observed data is obtained. This was the original approach of Streeter and Phelps, and was also employed in the determination of reaeration rate 
data analyzed by DoBbins, [2-5] O'Connor [5, 6], and CHURChill et al. [7], all of whom were interested in obtaining a predictive correlation between hydraulic properties of the stream and observed reoxygenation rates. Unfortunately, the respiration rates of bottom plants and bacterial slimes were not susceptible to independent measurement and, together with the fluctuating rate of photosynthetic $\mathrm{O}_{2}$ production, constituted a potential source of error lying outside the simple oxygen-sag model of Streeter and Phelps used in all of these works. More recently Korvo and Korvo [8] have applied the elegant theory of parameter estimation in linear distributed systems to the modified (to include longitudinal diffusion) Streeter-Phelps equations. Though the model again was over-simplified, insofar as photosynthesis and respiration of attached organisms on the bottom were ignored, the method can undoubtedly be extended to cover these processes, as well, and will perhaps become the method of choice when one has available a sufficient mass of 'distributed' data. HORNBERGER and KELLEY [9] have developed a method for estimating photosynthetic $\mathrm{O}_{2}$ production by suspended organisms from the dynamic evolution of the vertical oxygen and temperature gradients in lakes and very slow-moving streams. This method is, of course, not applicable to well-stirred rivers where the gradient essentially vanishes except at the fluid boundaries. It should also be mentioned that O'CONNOR [10] has developed equations for the fluctuating rate of photosynthetic $\mathrm{O}_{2}$ production in well-stirred 1-dimensional rivers, but has not come to grips with the question of random modulation (by clouds) of the light intensity driving the photosynthesis, and does not explicitly mention the potential significance of the 'phase lag' and 'amplitude' of the dissolved oxygen response for determining directly the rate parameters of the model, including reaeration, photosynthesis, and respiration, as will be discussed in detail below. Other indirect methods have been reviewed by VINBERG [11].

The direct methods consist at the present time exclusively of radioactive tracer measurements of gas exchange rates in situ, a technique pioneered by Tsivocrou et al. [12-14]. Although a thorough comparison of tracer gas and $\mathrm{O}_{2}$ exchange rates under a wide range of laboratory conditions was originally necessary to establish that a constant proportionality always existed between them $[13,16]$, that work may be regarded as satisfactorily concluded, at least for the most commonly used isotope $\mathrm{Kr}^{85}$. Even though the data that have been obtained by this technique are extremely valuable, especially in the matter of demonstrating the dramatic increase in reaeration rate associated with waterfalls, weirs, and white-water reaches, the method is not without its disadvantages, most of which are associated with the radioactivity of the tracer itself. For any river of significant size, that is with a flow rate of 1,000 cubic feet (or 27 cubic meters) per second or more, the total radioactive dose required is so large that special precautions must be taken to protect personnel involved, and the site of dosing the stream must be chosen far away from intakes for municipal water supplies and recreation areas [15]. Furthermore, in some regions (e.g. Switzerland) it is forbidden by law to inject radionuclides of any kind into the water for any purpose. The cost of the radionuclides and associated laboratory and field work is also considerable [17], amounting to more than $\$ 1,000$ per measurement, not counting capital investments for equipment. For these reasons it seems that the radioactive tracer method is not well-suited to large numbers of measurements on a multitude of streams and rivers. However, it may well prove to be the 
case that the direct method can also be implemented with stable isotopes using massspectrometry for analysis. The present commercial availability of relatively inexpensive portable helium mass-spectrometers in the form of vacuum leak detectors gives some hope that direct measurements of helium exchange rates in rivers may be easily and inexpensively performed. Tsivoglou [16] has already demonstrated the constant proportionality between $\mathrm{He}^{4}$ and $\mathrm{Kr}^{85}$ exchange rates (hence also $\mathrm{He}^{4}$ and $\mathrm{O}_{2}$ ) under a variety of experimental conditions.

Although the oxygen exchange rate is in itself an important parameter for understanding the self-purification process in rivers, the rate of oxygen production by photosynthesis and, especially, the total respiration rate of a stream are also important, not only for understanding the self-purification process, but also as direct monitors of water quality. Indeed, recent work of KoIvo and KoIvo [8] has been directed at monitoring BOD in rivers from the time-evolution of dissolved oxygen alone. In addition, the total photosynthesis and respiration rates, and their variation throughout the year, are of fundamental interest to aquatic biology in general. However, knowledge of the reaeration rates of streams from direct measurements still has not led to the estimation of photosynthesis and total respiration rates. Similarly, the various direct measurements of BOD (biological oxygen demand) or TOC (total organic carbon) have not permitted an estimation of the total respiration rate, biological and chemical, due to both suspended and bottom-fixed agents. Certainly, if one knew the total respiration rate as well as the initial rate of oxygen consumption by a liter of river water (isolated from both atmosphere and river bottom), then by subtracting the latter from the former an estimate of the rate of respiration by bottom-fixed agents could be obtained. Since the respiration rate of bottom-fixed agents appears to be inaccessible by direct measurement, a knowledge of the total respiration rate, or total rate of consumption of oxygen, by a river is essential for determining respiration due to bottom agents alone.

We wish to propose here a simple indirect method for determining simultaneously (i) the oxygen exchange rate; (ii) the average rate of photosynthetic oxygen production; and (iii) the total respiration rate in an ideal, well-stirred river from the continuous data record of a single oxygen electrode and a knowledge of the mean temperature. It has been demonstrated by direct methods [14] that at least in certain streams (e.g. Patuxent River in Maryland and South River in Georgia) the exchange rate is approximately uniform (i.e. to within $\pm 30 \%$ ) over rather long stretches of river up to 12 hours or more of flow time. Such ideal smooth rivers with nearly uniform exchange rates are in marked contrast to those with highly irregular longitudinal channel profiles which exhibit variations of more than a factor of 10 in exchange rate from one location to another, being much greater in regions of high energy dissipation in the water (e.g. the Flint River in Georgia [14]). The method proposed here should be applied only to streams for which the flow is reasonably smooth with no waterfalls, weirs, or dams within two or three oxygen exchange 'lifetimes' on the upstream side of the electrode. Examples of difficulties encountered when this condition is not met are discussed below.

The basic idea employed here is an old one originally proposed in a rather different connection by EINSTEIN [18] in 1920. When a chemical reaction in the steady-state is subjected to a cosinusoidal (in time) external perturbation of any of the thermo- 
dynamic variables, the periodic response of the reactants to the perturbation will lag behind it in phase (or time) by a particular amount depending upon the finite speed of the chemical process itself, and will exhibit an amplitude of oscillation reflecting the fundamental susceptibility or inducibility of the system by the perturbation. In the example considered here the 'chemical reaction' is the exchange of $\mathrm{O}_{2}$ between air and water, the 'steady-state' would be that maintained in the presence of respiration and the average (over day and night) photosynthesis, while the periodic (24hour) oscillation of the sunlight-induced photosynthesis is the 'cosinusoidal external perturbation'. The (24-hours) periodic component of the dissolved oxygen is, then, the 'response' of the reactant to the perturbation. It will be shown in detail below how the time lag between the sunlight maximum and the dissolved oxygen maximum can be used to infer the gas exchange rate, and how the amplitude of the periodic oxygen response can be used to infer the photosynthesis rate, and finally how the total respiration rate can then be inferred from the average (over all times) dissolved oxygen concentration.

The elementary model and its simple solution are described in Section 2 below. The critical problem of how to deal with the effects of clouds, smoke, smog, fog and other random modulations of the 'ideal' sunlight curve is discussed in section 3 . The use of time-delayed correlations, or the cross-correlation function, between ideal sunlight and dissolved oxygen to select-out the desired 24-hour component of the dissolved oxygen is then described in section 4. Practical application of this technique to data for several Swiss rivers is described in section 5. A discussion of these results is presented in section 6 . Finally in section 7 the extension of this technique to the more complicated problem of determining total carbonate dynamics from the daily variations in $\mathrm{pH}$ is discussed, and results obtained from the Aare-Bern, Mar-74 data for the gas exchange rate of $\mathrm{CO}_{2}(\mathrm{aq})$ and for the photosynthetic yield ratio (oxygen molecules produced to carbonate molecules consumed) are presented.

\section{The Model}

It is desirable to adopt the simplest possible model at the outset for the main development, and to introduce additional sophistications only after the basic properties of this model have been established. In this case the simplest possible river is one which has no end-boundaries, and which is localized in such a small geographical area that the incident light intensity at any time is the same over the entire river. $\mathrm{A}$ stream flowing around a circular channel would be a satisfactory pictorial representation. It is further assumed that the river channel is completely homogeneous in the sense that the exchange rate, respiration rate, and photosynthesis rate are the same in all sections of the river. Under these conditions the dissolved $\mathrm{O}_{2}$ concentration is independent of position and is a function only of the time. The equation-of-motion obeyed by the dissolved oxygen is assumed to be

$$
\frac{\partial \mathrm{O}(t)}{\partial t}=-\overleftarrow{k} \mathrm{O}(t)+\vec{k} \mathrm{O}_{A}+\alpha I(t)-\beta
$$


where the symbol $\mathrm{O}(t)$ has been used to denote the concentration $\left[\mathrm{O}_{2}\right]$ of dissolved oxygen (mg/l) at time $t, \vec{k}$ is the outgassing constant $\left(\mathrm{h}^{-1}\right)$, or exchange rate, $\vec{k}$ is the invasion constant $\left(\mathrm{h}^{-1}\right), \mathrm{O}_{A}$ denotes the constant concentration $(\mathrm{mg} / \mathrm{l})$ of atmospheric oxygen, $\beta$ denotes the constant total respiration rate $[\mathrm{mg} /(1 \mathrm{~h})], I(t)$ is the instantaneous light intensity incident upon the upper surface of the river, and $\alpha I(t)$ is instantaneous rate of photosynthesis $[\mathrm{mg} / \mathrm{l} \mathrm{h})]$ at time $t$. The following assumptions are implicit in (1) above:

(i) $\vec{k}, \vec{k}, \alpha, \beta$ are independent of position along the river.

(ii) The flow rate is sufficiently large that the stream is very well mixed, in particular possessing no significant vertical gradients in $\mathrm{O}_{2}$ concentration.

(iii) The photosynthesis is always light-limited throughout the day, and the concomitant release of oxygen into the river water is instantaneous.

(iv) The effect of dilution by ground water is contained in $\beta$, so it actually represents a lower limit to the true respiration rate.

By assumption (iii) it is implied that critical nutrients (in particular inorganic phosphate) are not exhausted in the course of a sunny day, as is often the case in lakes. For the well-behaved rivers that we have examined the daily peak in dissolved oxygen concentration is generally symmetrical in shape, which would not be the case if photosynthesis were nutrient-limited late in the day. Also the cloud fluctuations modulating the sunlight are observed to have roughly comparable effects during both the morning and late afternoon hours, which also argues for a strictly lightlimited photosynthesis. From the data obtained by EichenBERger[19] on the small artificial stream channels at Tüffenwies (Switzerland), where the light intensity has been recorded simultaneously along with the dissolved oxygen, it is apparent that the dissolved oxygen increases very rapidly following an abrupt increase in sunlight, any lag being certainly less than just a few minutes. Thus, the assumption of instantaneous release of the oxygen is probably quite realistic, so long as the air-water oxygen exchange times $\tau_{0}=(\overleftarrow{h})^{-1}$ in which we are interested are significantly longer than the oxygen release time, as is certainly the case in these investigations.

The assumption that the respiration rate $\beta$ is independent of the dissolved oxygen concentration is generally valid, provided that $\left.\mathrm{O}_{2}\right]$ values greater than $3 \mathrm{mg} / \mathrm{ml}$ prevail, and that respiration deep within thick films and large flocs is negligible, which will probably be the case in most streams [20]. Only an exceptionally heavy pollution load could maintain such a low dissolved oxygen concentration in a wellstirred stream.

It is assumed for the moment that in the absence of clouds the light intensity is given by a constant plus a 24-hour cosine,

$$
I(t)=\frac{I_{\mathbf{0}}}{2}(1+\cos \Omega t),
$$

where $\Omega=2 \pi / 24$ and the time $t$ is reckoned in hours. Actually, even in ideal weather the sunlight curve contains additional frequency components, as will subsequently be discussed in more detail. Furthermore, it is assumed that the sunlight of (2) has been imposed for such a long time that any initial transients associated with 'turning- 
on' the light have long since died away. Upon separating both $\mathrm{O}(t)$ and $I(t)$ into their stationary average, or steady-state, and time-dependent parts, according to

$$
\begin{gathered}
\mathrm{O}(t)=\overline{\mathrm{O}}+\Delta \mathrm{O}(t) \\
I(t)=\bar{I}+\Delta I(t)=\frac{I_{\mathbf{0}}}{2}+\frac{I_{0}}{2} \cos \Omega t,
\end{gathered}
$$

and substituting in (1) above the following two equations are obtained:

$$
\begin{gathered}
\overrightarrow{\mathrm{O}=}=\frac{\vec{k} \mathrm{O}_{A}}{\overleftarrow{k}}-\frac{\beta}{\overleftarrow{k}}+\frac{\alpha I_{\mathrm{o}} / 2}{\overleftarrow{k}}=\mathrm{O}_{\mathrm{eq}}-\frac{\beta}{\overleftarrow{k}}+\frac{\alpha I_{0} / 2}{\overleftarrow{k}}, \\
\frac{\partial \Delta \mathrm{O}(t)}{\partial t}+\overleftarrow{k} \Delta \mathrm{O}(t)=\frac{\alpha I_{0}}{2} \cos \Omega t,
\end{gathered}
$$

where in (5) it has been recognized that $\vec{k} \mathrm{O}_{A} / \vec{k} \equiv \mathrm{O}_{\mathrm{eq}}$ is just the dissolved oxygen concentration that would prevail at (chemical) equilibrium (or saturation) at the corresponding temperature in the river in the absence of respiration and photosynthesis.

The solution of (6) may be readily effected by standard methods (including Fourier transformation), and is found to be

$$
\Delta \mathrm{O}(t)=A \cos \Omega(t-T),
$$

wherein the time-delay of the response is

$$
T=\frac{1}{\Omega} \tan ^{-1}\left(\frac{\Omega}{\stackrel{\leftarrow}{k}}\right)
$$

and the amplitude of the response is

$$
A=\frac{\alpha I_{0} / 2}{\left(\Omega^{2}+\overleftarrow{k^{2}}\right)^{1 / 2}},
$$

as may be verified by direct differentiation. The complete solution for the dissolved oxygen is, of course, the sum of (5) and (7). The meaning of the time-delay and amplitude are indicated schematically in Figure 1. The dissolved oxygen is displaced to the right (i.e. to later times) of the sunlight curve by the time-delay $T$, and the amplitude of oscillation of the dissolved oxygen response is proportional to $\alpha I_{0} / 2$. Since the maximum amplitude of the sunlight occurs at geographic noon, one need only determine the displacement of the oxygen maximum from geographic noon to obtain the delay time $T$ and, hence, an estimate of the exchange rate $\overleftarrow{k}$ using (8). From the measured amplitude of the oscillation (i.e. one-half the trough-to-crest value) $A$ and a knowledge of $\overleftarrow{k}$ one may determine the value of $\alpha I_{0} / 2$ using (9). Then, from the measured average, or steady-state, value $\bar{O}$ together with a knowledge of $\overleftarrow{k}, \alpha I_{0}$, and the saturation value $\mathrm{O}_{\mathrm{eq}}$, one may obtain $\beta$ using (5).

Thus, measurement of the three parameters $T, A$ and $\bar{O}$ in conjunction with the three equations (8), (9) and (5) permits determination of the three unknown rate 
parameters $\overleftarrow{k}, \alpha I_{0} / 2$, and $\beta$, provided that the saturation value $\mathrm{O}_{\text {eq }}$ is known (it can be found in tables, if only the temperature is known). An important feature of this model is that it is not necessary to know the actual light intensity $I_{0}$ to complete the above analysis, since the quantity $\alpha I_{0} / 2$ is obtained directly from the measured amplitude $A$ (and also $\Omega$ and $\overleftarrow{k}$ ). Clearly, the average (over day and night) rate of photosynthesis is just $\alpha I^{-}=\alpha I_{0} / 2$, and the rate of photosynthesis at any time is evidently just $\left(\alpha I_{0} / 2\right) \cdot(1+\cos \Omega t)$.

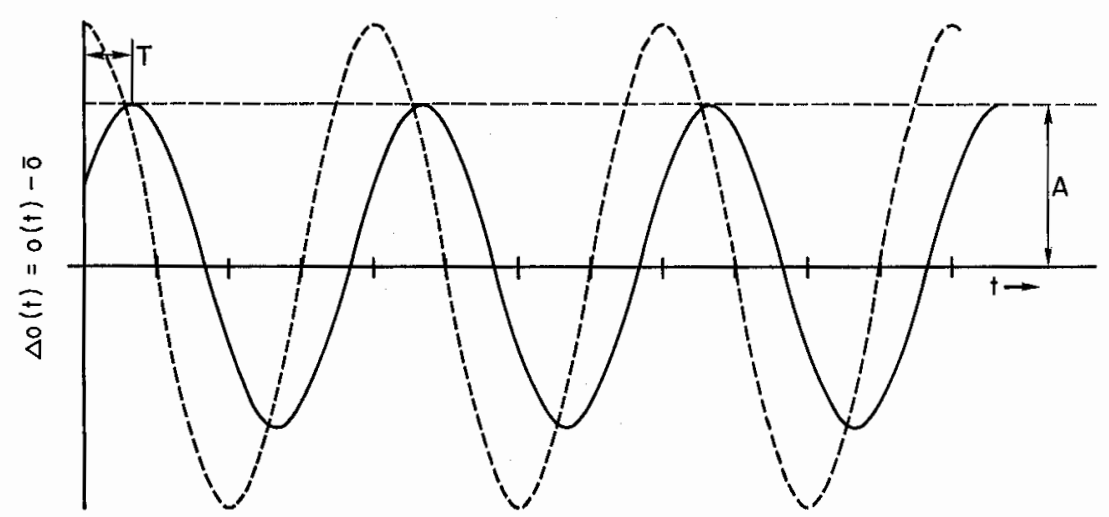

Fig. 1. Schematic plot of dissolved oxygen response $\Delta O(t) \equiv O(t)-\bar{O}$ (solid line) given by (7) versus time $t$, superimposed on plot of variation in light intensity $\Delta I(t)$ (dashed line) versus $t$. The meaning of the time-delay $T$ and the amplitude $A$ of the dissolved oxygen response to the oscillating light intensity is illustrated.

Abb. 1. Schematische Darstellung der Sauerstoffkonzentration $\Delta O(t) \equiv O(t)-\bar{O}$ (durchgezogene Linie) in Funktion der Zeit, gegeben durch (7), sowie, überlagert, die Lichtintensität $\Delta I(t)$ punktierte Linie) in Funktion der Zeit. Die Bedeutung der Zeitverzögerung $T$ und der Amplitude $A$ des gelösten Sauerstoffs in Funktion der Lichtintensität wird illustriert.

If one knew also the actual light intensity $I_{0}$, then one could determine finally the coefficient $\alpha$, which is just the photosynthetic efficiency expressed as $\mathrm{mg} / \mathrm{l}$ of oxygen introduced into the stream per erg/ $\mathrm{cm}^{2}$ of solar energy incident upon its upper surface. Measurements of incident solar energy have only recently been initiated on the Aare at Bern, so throughout the analysis presented here the constant $\alpha$ will remain undetermined.

As a final point we note that the maximum allowed value of $\tan ^{-1}(\Omega / \vec{k})$ is $\pi / 2$, corresponding to a maximum allowed time delay of $T=6 \mathrm{~h}$, consistent with the model assumed here. The observation of longer delays, as found in the June-1972 data for the Limmat River at Baden, is an indication that some non-random periodic agent in addition to sunlight is acting to influence the dissolved oxygen record. According to the model a maximum in dissolved oxygen occurs when the rate of increase exactly balances the rate of loss and, therefore, should only occur during the daylight hours. 


\section{Random Weather Modulations of the Sunlight}

Although the oxygen data records of certain rivers during some seasons might be nearly as simple in form as the schematic displayed in Figure 1, it may generally be expected that random fluctuations in cloud cover, atmospheric dust, etc., will produce pronounced alterations in the exact form of the sunlight curve, and consequently also in the dissolved oxygen record, over any given period of time. These effects are treated here by assuming that the real light intensity $I_{R}(t)$ at any instant $t$ is related to the ideal intensity $I(t)$ according to

$$
I_{R}(t)=(1-R(t)) \cdot I(t),
$$

where the opacity factor $R(t)=\bar{R}+\Delta R(t)$ consists of an average (over the time interval in question) part $\bar{R}$ and a (nearly) Gaussian randomly fluctuating part $\Delta R(t)$. The value of $R(t)$ must be generally less than 1.0 to prevent the occurrence of negative intensities, so that $\Delta R(t)$ cannot be a strictly Gaussian random variable, but must be bounded on the positive side. However, we shall ignore this difficulty in the ensuing development.

Employing the previous expression 2 for the light intensity there results

$$
I_{R}(t)=(1-\bar{R})\left(I_{0} / 2\right)(1+\cos \Omega t)-\Delta R(t) I_{0} / 2-\Delta R(t)\left(I_{0} / 2\right) \cos \Omega t .
$$

It should be noted that the first term on the right is just $(1-\bar{R})$ times the light intensity employed previously. It will be shown in the subsequent development that even though the second and third terms on the right in (11) make complicated contributions to $\mathrm{O}(t)$, the method of cross-correlations introduced below enables one to effectively select-out only that part of the dissolved oxygen response arising from the first term in (11).

The particular time-record of $\Delta R(t)$ over the experimental interval (1 month in the investigations reported here) from 0 to $S$ may, according to Fourier's Theorem, be written as a sum of sine and cosine functions of discrete frequencies, thus

$$
\Delta R(t)=\sum_{n=1}^{\infty}\left[a_{n} \cos \omega_{n} t+b_{n} \sin \omega_{n} t\right],
$$

wherein $\omega_{n}=2 \pi \mathrm{n} / S$, and the amplitudes may be determined (not necessary for this development) from the actual $\Delta R(t)$ record according to the standard formulae.

$$
\begin{aligned}
& a_{n} \equiv \frac{2}{S} \int_{0}^{S} \Delta R(t) \cos \omega_{n} t d t \\
& b_{n} \equiv \frac{2}{S} \int_{0}^{S} \Delta R(t) \sin \omega_{n} t d t .
\end{aligned}
$$

If one replaces $I(t)$ in (1) with $I_{R}(t)$ then (5) and (6) become

$$
\overrightarrow{\mathrm{O}}=\mathrm{O}_{\mathrm{eq}}-\frac{\beta}{\bar{k}}+\frac{(1-\bar{R}) \alpha I_{0} / 2}{\overleftarrow{k}}
$$




$$
\frac{\partial \Delta \mathrm{O}(t)}{\partial t}+\stackrel{\leftarrow}{k} \Delta \mathrm{O}(t)=(1-\bar{R})\left(\alpha I_{0} / 2\right) \cos \Omega t-\left(\alpha I_{0} / 2\right) \Delta R(t)-\Delta R(t)\left(\alpha I_{0} / 2\right) \cos \Omega t,
$$

where it is understood that $\Delta R(t)$ in $(15)$ is to be replaced by the Fourier series 12 . With the aid of standard trigonometric identities the third term on the right in (15) may be written as

$$
\begin{aligned}
\left(\alpha I_{0} / 2\right) \Delta R(t) \cos \Omega t= & \left(\alpha I_{0} / 2\right) \sum_{m=1}^{\infty}\left[\frac{a_{m}}{2}\left\{\cos \left(\omega_{m}+\Omega\right) t+\cos \left(\omega_{m}-\Omega\right) t\right\}\right. \\
& \left.+\frac{b_{m}}{2}\left\{\sin \left(\omega_{m}+\Omega\right) t+\sin \left(\omega_{m}-\Omega\right) t\right\}\right] .
\end{aligned}
$$

Because of the linear nature of the differential equation (15), each $\sin \omega t$ or $\cos \omega t$ driving term in the light intensity makes its own separate contribution independently of the others. The complete solution for the dissolved oxygen over the time interval 0 to $S$ is easily found to be

$$
\begin{aligned}
O(t)-\overline{\mathrm{O}}= & (1-\bar{R}) A \cos \Omega(t-T) \\
& -\sum_{n=1}^{\infty}\left\{B_{n} \cos \left(\omega_{n}\left(t-T_{n}\right)\right)+C_{n} \sin \left(\omega_{n}\left(t-T_{n}\right)\right)\right\} \\
& -\sum_{m=1}^{\infty}\left[D_{m}^{+} \cos \left(\omega_{m}+\Omega\right)\left(t-T_{m}^{+}\right)+D_{m}^{-} \cos \left(\omega_{m}-\Omega\right)\left(t-T_{m}^{-}\right)\right. \\
& \left.\quad+E_{m}^{+} \sin \left(\omega_{m}+\Omega\right)\left(t-T_{m}^{+}\right)+E_{m}^{-} \sin \left(\omega_{m}-\Omega\right)\left(t-T_{m}^{-}\right)\right],
\end{aligned}
$$

wherein

$$
\begin{array}{rlrl}
T_{n} & \equiv \frac{1}{\omega_{n}} \tan ^{-1}\left(\frac{\omega_{n}}{\overleftarrow{k}}\right) & T_{m}^{ \pm} \equiv \frac{1}{\left(\omega_{m} \pm \Omega\right)} \tan ^{-1}\left(\frac{\omega_{m} \pm \Omega}{\overleftarrow{k}}\right) \\
B_{n} \equiv \frac{\left(\alpha I_{0} / 2\right) a_{n}}{\left(\omega_{n}^{2}+\overleftarrow{k^{2}}\right)^{1 / 2}} & D_{m}^{ \pm} \equiv \frac{\left(\alpha I_{0} / 2\right)\left(a_{m} / 2\right)}{\left(\left(\omega_{m} \pm \Omega\right)^{2}+\overleftarrow{k}^{2}\right)^{1 / 2}} \\
C_{n} \equiv \frac{\left(\alpha I_{0} / 2\right) b_{n}}{\left(\omega_{n}^{2}+\hbar^{2}\right)^{1 / 2}} & E_{m}^{ \pm} \equiv \frac{\left(\alpha I_{0} / 2\right)\left(b_{m} / 2\right)}{\left(\left(\omega_{m} \pm \Omega\right)^{2}+\overleftarrow{k^{2}}\right)^{1 / 2}} .
\end{array}
$$

The important point to notice about equation (17) is that none of the terms in the $m$-sum has exactly the angular frequency $\Omega$, and that only for a single term $\omega_{n}=\Omega$ in the $n$-sum is there an exact frequency match. Furthermore, since the fluctuating cloud modulation, or opacity, $\Delta R(t)$ has been assumed to be a simple Gaussian random variable, only a negligible fraction of the total amplitude in its power spectrum can appear at any single frequency, which is just another way of saying that the magnitudes $\left|a_{n}\right|$ and $\left|b_{n}\right|$ must be extremely small compared to 1 , hence also $B_{n}$ and $C_{n}$ must be negligible compared to $A$. Thus, if we can find a way to extract only those terms with angular frequency $\Omega$ from the dissolved oxygen record, then we shall have essentially isolated the contribution of the $(1-\bar{R}) A$ $\cos \Omega(t-T)$ term from all the others, and the problem will once more be reduced to 
the simple form of section 2 . There are two distinct ways in which this isolation might be achieved, as described in the following paragraphs.

One can determine the amplitudes of the $\cos \Omega t$ and $\sin \Omega t$ terms by simple projection, that is multiplying the dissolved oxygen record $\mathrm{O}(t)$ by either $\cos \Omega t$ or $\sin \Omega t$, respectively, and integrating the product from 0 to $S$, and finally multiplying by $2 / S$ ) a procedure implicit in equation (13a), (b) with $\Delta \mathrm{O}(t)$ in place of $\Delta R(t)$. Then, these $\sin \Omega t$ and $\cos \Omega t$ terms may be recombined to a single cosine term with a phase lag and amplitude, as before. This procedure is not recommended for two reasons, the most important of which is that one obtains no 'feedback' information regarding the validity, or applicability, of this simple model to the stream in question. For example, if there exist secondary maxima occurring daily in the dissolved oxygen record, but hidden well enough by the cloud noise to escape detection by eye, then neither visual inspection nor the Fourier projection will reveal that in this case the simple model is not applicable. (We have already encountered such an example in the January-1972, data for the Aare River taken at the Brugg measuring station). In using indirect methods one should generally strive to utilize every means possible to verify the validity of the model in each case. The second reason for not recommending this procedure is that it furnishes no estimate of the errors involved, or of the reliability of the numbers obtained. Given a noisy, or cloudy, dissolved oxygen record, there is always the question of how many days' data are necessary to give a reasonably precise estimate of the time-lag $T$ and amplitude $A$. Simply projecting out the amplitudes of the $\cos \Omega t$ and $\sin \Omega t$ terms from a particular record will always give numbers for $T$ and $A$, but offers no information about whether the original data record was of sufficient length to yield reliable values.

For the reasons cited above we have eschewed the simple projection procedure, and have instead adopted a method for determining the time-delayed correlations between ideal sunlight and dissolved oxygen that effectively averages out the random effects of the clouds. This method is the central topic of the next section.

\section{The Gross-Gorrelation Function between (Ideal) Sunlight and Dissolved Oxygen}

Given any pair of observables (e.g. sunlight and dissolved oxygen) which have been simultaneously observed at a sequence of regularly spaced times $t_{0}, t_{1}=1 \cdot \delta t, t_{2}$ $=2 \cdot \delta t, \ldots, t_{n}=n \cdot \delta t, t_{N}=N \cdot \delta t$, the test for correlation between them involves calculating the well-known correlation coefficient, which apart from the customary 'normalization' constant is defined by

$$
C(\mathrm{O}) \equiv \frac{1}{(N+1)} \sum_{i=0}^{N}\left(I\left(t_{i}\right)-\bar{I}\right) \cdot\left(\mathrm{O}\left(t_{i}\right)-\overline{\mathrm{O}}\right)
$$

where $\left\{I\left(t_{0}\right), I\left(t_{1}\right), \ldots\right\}$ and $\left\{\mathrm{O}\left(t_{0}\right), \mathrm{O}\left(t_{1}\right), \ldots\right\}$ are the data sets for sunlight and dissolved oxygen, respectively, and $\bar{I}$ and $\bar{O}$ are, of course, the respective averages, 
defined by

$$
\begin{gathered}
\bar{I} \equiv \frac{1}{(N+1)} \sum_{i=0}^{N} I\left(t_{i}\right) \\
\overline{\mathrm{O}} \equiv \frac{1}{(N+1)} \sum_{i=0}^{N} \mathrm{O}\left(t_{i}\right) .
\end{gathered}
$$

One may also inquire whether the values of one variable (e.g. the sunlight) are correlated with those values of the other (e.g. dissolved oxygen) occurring at a time later by the amount $\tau=l \cdot \delta t$. For this case the appropriate generalization of (18) is

$$
C(\mathbf{l} \cdot \delta t) \equiv \frac{1}{(N-l+1)} \sum_{i=0}^{N-l}\left(I\left(t_{i}\right)-\bar{I}\right) \cdot\left(\mathrm{O}\left(t_{i+l}\right)-\overline{\mathrm{O}}\right),
$$

which in the limit of small time-intervals between data points may be expressed in integral form as

$$
C(\tau) \equiv \frac{1}{S} \int_{0}^{S}(I(t)-\bar{I}) \cdot(\mathrm{O}(t+\tau)-\overline{\mathrm{O}}) d t .
$$

The quantity $\mathrm{C}(\tau)=C(l \cdot \delta t)$ is the cross-correlation function between the sunlight and dissolved oxygen records, and its behavior as a function of $\tau$ yields information regarding either the persistence or periodicity (in time) of correlations between these two variables. It should be noted that the average of $C(\tau)$ computed over a sufficiently large interval of $\tau$ is essentially zero, implying that $C(\tau)$ must itself either vanish or manifest periodic oscillations at large values of $\tau$.

If we introduce a quantity proportional to the ideal light intensity

$$
j(t)=(1 / 2)(1+\cos \Omega t)
$$

and calculate the theoretical cross-correlation function between $j(t)$ and the randomly modulated dissolved oxygen record of (17) we find

$$
C(\tau) \equiv \frac{1}{S} \int_{0}^{S}(j(t)-\bar{\jmath}) \cdot(\mathrm{O}(t+\tau)-\overline{\mathrm{O}}) d t=(1-\bar{R}) \frac{A}{4} \cos [\Omega(\tau-T)]
$$

still ignoring $C_{n}, B_{n},\left(\omega_{n}=\Omega\right)$ in comparison with $A$. Thus, this theoretical crosscorrelation function selects out just the 24-hour-period component of the dissolved oxygen record from the background of contributions of other frequency components.

The actual shape of the ideal sunlight curve is more complicated than the simple constant plus 24-hour cosine assumed till now. In practice the following form has been employed for the shape of the sunlight curve:

$$
j(t)=\left\{\begin{array}{cc}
\frac{1}{2}\left[1+\cos \left(\frac{2 \pi}{12} t\right)\right] ; & -6 \leq t \leq 6 \\
0 ;-12 \leq t<-6 ; & 6 \leq t \leq 12
\end{array}\right\},
$$

in which the 0 -value of the time is taken precisely at the local geographic noon, which occurs at about $12.45 \mathrm{~h}$ official Zürich time for most of the measuring stations 
involved in this study. A single day from 0 to $24 \mathrm{~h}$ encompasses the interval -12 $\leq t \leq 12$ on the sunlight time-scale of equation (23). A similar expression has also been employed by GÄCHTER [21] in a study of primary production of plankton in the Lake of Lucerne (Vierwaldstättersee). One may also express $j(t)$ in terms of its Fourier series as

$$
j(t)=j_{0}+i_{1} \cos \left(\frac{2 \pi}{24} t\right)+i_{2} \cos \left(\frac{2 \pi}{12} t\right)+j_{3} \cos \left(\frac{2 \pi}{8} t\right)+\cdots,
$$

where the amplitudes $j_{n}$ of the principal components have been explicitly evaluated using expressions analogous to (13a) (b) with $j(t)(23)$ in place of $\Delta R(t)$, thus

$$
j_{0}=0.25 \quad j_{1}=0.425 \quad j_{2}=0.25 \quad j_{3}=0.085 \text {. }
$$

In view of the predominance of the first three terms in (24), that is the average value and amplitudes of the $24-\mathrm{h}$ and $12-\mathrm{h}$ components, the higher frequency components will be neglected, a practice in keeping with the precedent of O'CONNOR [10]. The expression 2 for the ideal light intensity employed in (10), (11), (14), (15), (16), (17) must now be replaced by the Fourier series corresponding to expression (24), thus

$$
I(t)=j_{0} I_{0}+j_{1} I_{0} \cos \left(\frac{2 \pi}{24} t\right)+i_{2} I_{0} \cos \left(\frac{2 \pi}{12} t\right) .
$$

With this substitution the final expression for the steady-state value $\overline{\mathrm{O}}$ becomes

$$
\overline{\mathrm{O}}=\mathrm{O}_{\mathrm{eq}}-\frac{\beta}{\overleftarrow{k}}+\frac{(1-\bar{R}) \alpha j_{0} I_{0}}{\overleftarrow{k}} .
$$

In addition the 24-h cosine component contributes a solution of the same form as (17) to the dissolved oxygen fluctuations, but all terms will be reduced in amplitude by the ratio $j_{1} / 0.5$. The 12 -h component of the light will also make a separate contribution of the form of (17), but with $2 \Omega=2 \pi / 12$ everywhere in place of $\Omega$, and with amplitudes also reduced by the ratio $j_{2} / 0.5$.

The important point to observe is that in the calculation of the cross-correlation function between $j(t)$ and the dissolved oxygen only matching frequency components contribute, and again only the 24-hour and 12-hour terms corresponding to the first term in (17) make a significant contribution to the result, thus

$$
\begin{aligned}
C(\tau) \equiv \frac{1}{S} \int_{0}^{S}(j(t)-\bar{j}) \cdot(\mathrm{O}(t+\tau) & -\overline{\mathrm{O}}) d t=j_{1}^{2} \frac{(1-\bar{R}) \alpha I_{0}}{2\left(\Omega^{2}+\overleftarrow{k}^{2}\right)^{1 / 2}} \cos \left(\frac{2 \pi}{24}\left(\tau-T_{1}\right)\right) \\
& +j_{2}^{2} \frac{(1-\bar{R}) \alpha I_{0}}{2\left(4 \Omega^{2}+\bar{k}^{2}\right)^{1 / 2}} \cos \left(\frac{2 \pi}{12}\left(\tau-T_{2}\right)\right),
\end{aligned}
$$

where also

$$
T_{1}=\frac{1}{\Omega} \tan ^{-1}\left(\frac{\Omega}{\overleftarrow{k}}\right) ; \quad T_{2}=\frac{1}{2 \Omega} \tan ^{-1}\left(\frac{2 \Omega}{\overleftarrow{k}}\right)
$$

Because the ratio of amplitudes of the 24-h and 12-h components in the crosscorrelation function is the square of the ratio of their amplitudes in the ideal sunlight 
record, the relative dominance of the $24-\mathrm{h}$ component is significantly enhanced. We have employed two different methods for analyzing the cross-correlation functions between our assumed sunlight curve $j(t)$ and the dissolved oxygen.

(I) Under the assumption that the 24-h component in the cross-correlation function is dominant, the 12-h component is then neglected, and the computed cross-correlation function is analyzed in terms of the simple formula

$$
C(\tau)=A_{1} \cos \frac{2 \pi}{24}\left(t-T_{1}\right),
$$

where, of course, $T_{1}$ is given by (29) and

$$
A_{1}=\frac{(0.425)^{2}(1-\bar{R}) \alpha I_{0}}{2\left(\Omega^{2}+\bar{k}^{2}\right)^{1 / 2}} .
$$

The time-delay $T_{1}$ is taken simply as the displacement of the first maximum in $C(\tau)$ from the origin at $\tau=0$, while $\mathrm{A}_{1}$ is taken as one-half the vertical trough-tocreast displacement. As before, a determination of $T_{1}, A_{1}, \overline{\mathrm{O}}$ enables the calculation of $\overleftarrow{k},(1-\bar{R}) \alpha I_{0}$ and $\beta$ in conjunction with (29), (31) and (27). From a knowledge of $(1-\overline{\mathrm{R}}) I_{0}$ either the average photosynthesis rate over all times, or the average rate at any time of day may be easily calculated.

(II) Under the assumption that $C(\tau)$ contains just $24-\mathrm{h}$ and 12 -h components, the 24-h component may be easily isolated by the following procedure. With the aid of standard trigonometric identities (28) for $C(\tau)$ may be written in the form

$C(\tau)=a_{1} \cos \left(\frac{2 \pi}{24} t\right)+b_{1} \sin \left(\frac{2 \pi}{24} t\right)+a_{2} \cos \left(\frac{2 \pi}{12} t\right)+b_{2} \sin \left(\frac{2 \pi}{12} t\right)$,

where

$$
\begin{aligned}
\left(a_{1}^{2}+b_{1}^{2}\right)^{1 / 2} & =\frac{j_{1}^{2}(1-\vec{R}) \alpha I_{0}}{2\left(\Omega^{2}+\overleftarrow{k^{2}}\right)^{1 / 2}} \equiv A_{2} \\
a_{1} / b_{1} & =\overleftarrow{k} /(2 \pi / 24) \\
\left(a_{2}^{2}+b_{2}^{2}\right)^{1 / 2} & =\frac{j_{2}^{2}(1-\bar{R}) \alpha I_{0}}{2\left(4 \Omega^{2}+\overleftarrow{k}^{2}\right)^{1 / 2}} \equiv A_{22} \\
a_{2} / b_{2} & =\overleftarrow{k} /(2 \pi / 12) .
\end{aligned}
$$

From the expression (32) for $C(\tau)$ it is apparent that one can select certain times at which one or more of the terms in (32) vanish. It is easily verified that

$$
\begin{aligned}
& a_{1}=[C(0)-C(12)] / 2 \\
& b_{1}=[C(6)-C(18)] / 2 \\
& a_{2}=[C(0)+C(12)] / 2 \\
& b_{2}=[C(3)+C(15)] / 2,
\end{aligned}
$$

where the arguments of $C(\tau)$ are given in hours. Thus, from the computed crosscorrelation curve one may determine the Fourier coefficients readily from the 
values at a few specific times, as indicated above. The ratios $a_{1} / b_{1}$ and $a_{2} / b_{2}$ give $\vec{k}$ directly, using (34) and (36), and the extent of agreement between these values provides an indication of the accuracy of the assumptions invoked. The amplitudes $A_{2}$ and $A_{22}$ are also easily obtained from the coefficients $a_{1}, b_{1}, a_{2}, b_{2}$ using (33) and (35). The rest of the analysis is the same as that of method I.

All of our computed correlation functions have been analyzed by both methods. For well-behaved streams, such as the Aare at Bern, the difference in results between the two methods is not large, as will be shown below.

There remains the question of how the assumed shape of our sunlight curve compares with the actual sunlight record. We have just very recently obtained average hourly global radiation values (over all spectral components from near ultra-violet to near infra-red) computed for each month by VALko [22] from direct measurements at the Kloten meteorological station over the period from 1963 to 1972. Not surprisingly the winter months exhibit somewhat narrower profiles (i.e. shorter days) than our assumed curve, while the summer month profiles are rather broader (by about 2 hours at half-maximum), however the shape appears to be quite close for February and March and September and October, except for one significant difficulty. There apparently exists a significant asymmetry, or displacement of the real sunlight curve to earlier (geographic) times by about 15-20 minutes, perhaps due to the generation and accumulation of smoke and photochemical smog particulates during the day. Since the meteorological station is located right at the Zürich-Kloten airport and may not be sampling radiation curves representative of the Bern, Brugg, Mellingen, Baden and Rheinfelden oxygen-monitoring stations at which our data were collected, we have chosen for the present to ignore this difficulty unless, or until, the sunlight asymmetry is also confirmed by light-intensity measurements recently initiated at the oxygen-monitoring station in Bern. The general question of how to operationally define an 'ideal' sunlight curve from continuous measurements of the light intensity will be considered in a subsequent communication. It is clear that extensive light-intensity measurements are really a prerequisite for detailed studies of oxygen-dynamics and photosynthetic production in situ. However, it is important to note still that the magnitude of the sunlight intensity is not required for the analysis described here, as only the shape of the curve is used in these calculations.

\section{Raw Data, Calculations and Results}

Charts bearing the continuous output records of single amperometric oxygen electrodes [23] were supplied by the Swiss Federal Water Resource Bureau (Eidg. Amt für Wasserwirtschaft), A one-month period corresponds to about 4 meters of chart. These curves were digitized at $1 \mathrm{~mm}$ intervals (corresponding almost exactly to 12 minutes) in stretches of about 8 days and stored on magnetic tape using a Pencil Follower, System 2 (manufactured by D-MAC Ltd., High Wycombe, England), graciously provided by the Institute for National, Regional and Local Planning, Swiss Federal Institute of Technology, Zürich.

Interpretation, correction for gaps and overlaps, and reassembly of the records 


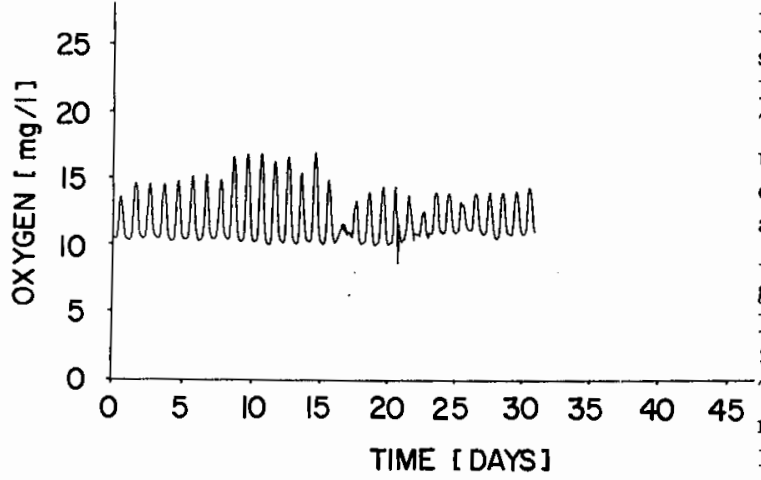

Fig. 2. Digitized raw data for dissolved oxygen in the Aare river at Bern for the month of March, 1974. The dissolved oxygen is given in units of $\mathrm{mg} / \mathrm{l}$ while the time unit is days. The digitization interval is almost exactly 12 minutes, or $0.2 \mathrm{~h}$. Abb. 2. Digitalisierte Rohdaten des gelösten Sauerstoffs in der Aare bei Bern im März 1974. Der gelöste Sauerstoff ist in $\mathrm{mg} / \mathrm{l}$ und die Zeit in Tagen angegeben. Das Digitalisierungsintervall beträgt ziemlich genau 12 Minuten oder 0,2 Stunden.

were effected by specially written programs using the CDC computer of the Swiss Federal Institute of Technology Zurich (ETHZ). The procedure adopted for gaps in the dissolved oxygen record was to insert logical minus zeros for the value of the oxygen concentration at the appropriate times. Then, in the computation of the cross-correlation function, the dissolved-oxygen record was tested in sequential hierarchy for joint numerical zero and logical zero, with the consequence that the correlation-products involving such joint zeros were omitted from the correlation function sum and were not counted in the normalization factor $(N-1+1)^{-1}$.

Examples of the best and the worst of our digitized raw data records, for the Aare at Bern and the Aare at Brugg, respectively, are displayed in Figures 2 and 3 . The daily oscillation of the dissolved oxygen in the Aare-Bern data is clearly apparent, while the Aare-Brugg data reveals very little indication of its underlying regularity to the unaided eye.

In assessing the quality of the raw data per se it should be mentioned that the river water is pumped up (rather quickly) from a depth between 1 and 2 meters below the surface and a position several meters from the bank into a receptacle containing the $\left[\mathrm{O}_{2}\right], \mathrm{pH}$, temperature, and conductivity electrodes. The polarographic Clark oxygen membrane electrodes (manufactured by Wissenschaftlich Technische

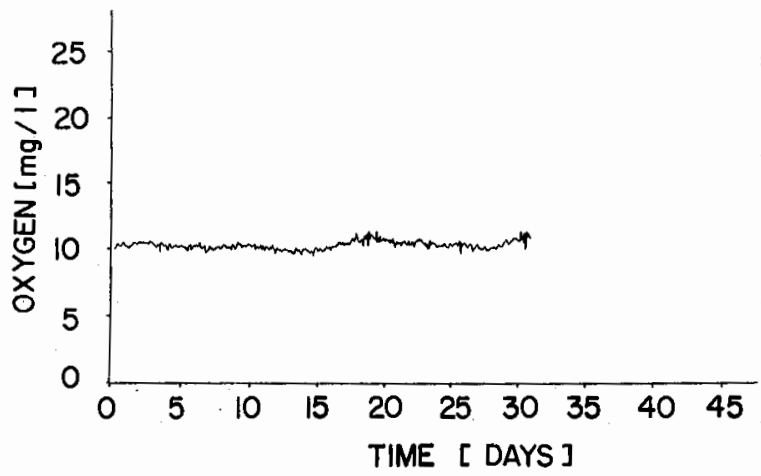

Fig. 3. Digitized raw data for dissolved oxygen in the Aare river at Brugg for the month of January, 1972. The dissolved oxygen is given in units of $\mathrm{mg} / \mathrm{l}$ while the time unit is days. The digitization interval is almost exactly 12 minutes, or $0.2 \mathrm{~h}$. Abb. 3. Digitalisierte Rohdaten des gelösten Sauerstoffs in der Aare bei Brugg im Januar 1972. Der gelöste Sauerstoff ist in $\mathrm{mg} / \mathrm{l}$ und die Zeit in Tagen angegeben. Das Digitalisierungsintervall beträgt ziemlich genau 12 Minuten oder 0,2 Stunden. 


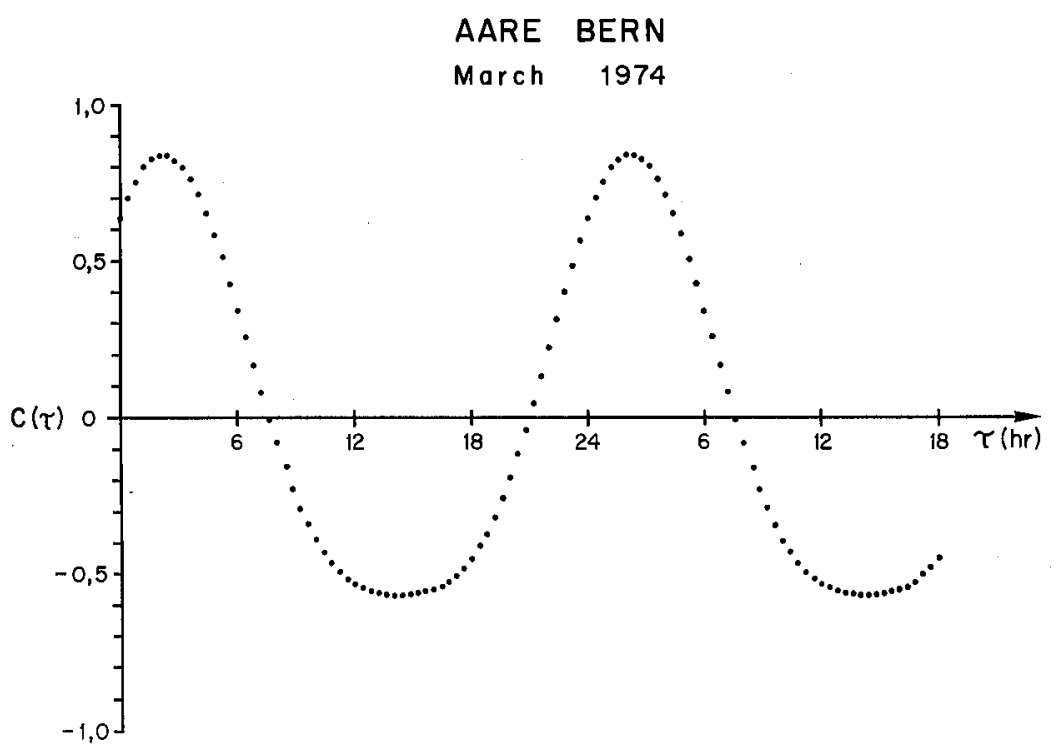

Fig. 4. Computed cross-correlation function between ideal (unitless) sunlight curve $j(t)$ (given by (23) and the Aare-Bern, March-74 dissolved oxygen record of Figure 2. Since only every second point is plotted, the time delay between points is 24 minutes, or $0.4 \mathrm{~h}$. The units of the crosscorrelation function are $\mathrm{mg} / \mathrm{ml}$.

Abb. 4. Berechnete Kreuzkorrelationsfunktion zwischen der idealen (dimensionslosen) Sonnenlichtkurve $j(t)$ (gegeben durch (23) und der in Figur 2 gegebenen Sauerstoffkonzentration der Aare bei Bern. Da nur jeder 2. Punkt gezeichnet wurde, beträgt die Zeitverzögerung zwischen den Punkten 24 Minuten oder 0,4 Stunden. Die Kreuzkorrelationsfunktion ist in $\mathrm{mg} / \mathrm{ml}$ angegeben.

Werkstätten, D-8120 Weilheim, Germany) were calibrated monthly, the reported average drift being about $0.2 \mathrm{mg} / 1$ with a maximum of $0.5 \mathrm{mg} / \mathrm{l}$.

The computed cross-correlation functions between the dissolved oxygen records of Figures 2 and 3 and the ideal sunlight function in (23) are presented in Figures 4 and 5, respectively. The dramatic rejection of random cloud 'noise' in the computed correlation function is immediately apparent from a comparison of Figures 3 and 5 . It should be mentioned that the computed correlation functions were generally calculated for time-delays up to six days and were essentially completely regular throughout. The corresponding data are given in Tables 1 and 2 on pages 162 and 163.

Pertinent data for the various rivers are presented in Table 1 , where the temperature, equilibrium value $\mathrm{O}_{\mathbf{e q}}$ of the dissolved oxygen, average (over all times in the month) value $\overline{\mathrm{O}}$ of the dissolved oxygen, amplitude $A_{1}$ (calculated as one-half the maximum trough-to-crest value of the cross-correlation function), and the time lag $T$ (by which the center of the first maximum in the cross-correlation function is displaced from the origin) have all been recorded in addition to the exchange constant $\overleftarrow{k}$, mean rate of photosynthetic oxygen production $0.25(1-\bar{R}) \alpha I_{0}$, and respiration rate $\beta$ all determined by the simple method I using (30), (31) and (27) with $j_{0}=0.25$. 
Corresponding data determined by method II in which the 24-hour component was first isolated by means of (37a), (b), and then the amplitude $A_{2}$ and exchange constant $\bar{k}$ determined using (33) and (34), are presented in Table 2 . The rows in the Tables marked by asterisks refer to cross-correlation functions in which either primary (e.g., Limmat-Baden, June-72) or secondary (e.g., Aare-Brugg, Jan-72, or Reuss-Mellingen, Jan-72) maxima occurring later than 6.00 p.m. (geographic time) were manifested. As remarked earlier, such peculiar behavior of the dissolved oxygen is outside the scope of our simple model, and possible reasons for this behavior will be discussed in the next section.

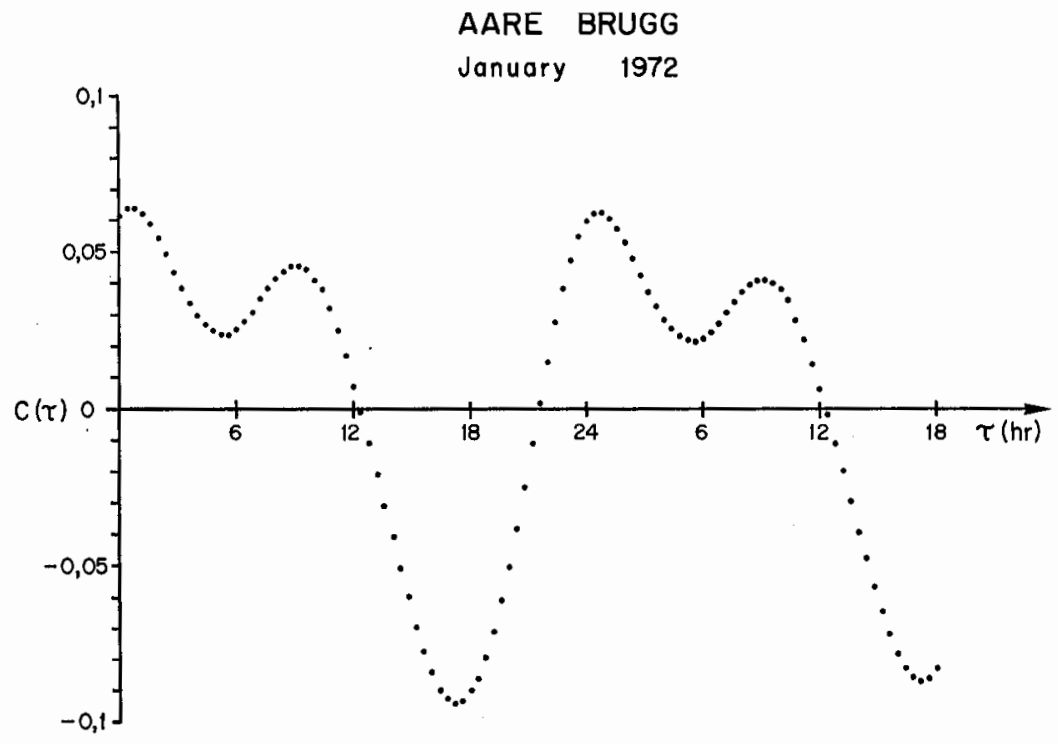

Fig. 5. Computed cross-correlation function between ideal (unitless) sunlight curve $j(t)$ (given by (23) and the Aare-Brugg, Jan-72 dissolved oxygen record of Figure 3. Since only every second point is plotted the time-delay between points is 24 minutes, or $0.4 \mathrm{~h}$. The units of the crosscorrelation function are $\mathrm{mg} / \mathrm{ml}$.

Abb. 5. Berechnete Kreuzkorrelationsfunktion zwischen der idealen (dimensionsiosen) Sonnenlichtkurve $j(t)$ (gegeben durch (23) und der in Figur 3 gegebenen Sauerstoffkonzentration der Aare bei Brugg. Da nur jeder 2. Punkt gezeichnet wurde, beträgt die Zeitverzögerung zwischen den Punkten 24 Minuten oder 0,4 Stunden. Die Kreuzkorrelationsfunktion ist in $\mathrm{mg} / \mathrm{ml}$ angegeben.

In most cases (excepting the Aare-Bern) the coefficients $a_{2}, b_{2}$ of the 12-hour component were found not to yield $\overleftarrow{k}$ values and amplitudes $A_{2}$ 'matching' those obtained from the 24-hour coefficients $a_{1}, b_{1}$. Frequently, either $a_{2}$ or $b_{2}$ was negative, thoroughly invalidating the model at that level. Thus, we have chosen to omit any detailed consideration of these $a_{2}, b_{2}$ values, except to note that by such a criterion only the Aare-Bern data conform more or less well to the model for both 12-hour and 24-hour components, and even there the situation is not truly satisfactory either. 


\section{Discussion of Results}

It is interesting to first compare the results obtained by methods I and II. If one ignores the data with asterisks, for which we know the model is seriously inadequate, it is then seen that the simple method I gives values rather close to those obtained by the slightly more complicated method II. The amplitudes $A_{1}, A_{2}$ obtained by the two methods are remarkably close, being within a few percent in every case. The exchange constants $k$ obtained by method I differ from those obtained by method II by various amounts up to as much as $40 \%$ for the Aare-Brugg, Sept-72 and RheinRheinfelden, Feb-72 data. However, for the Aare-Bern data, which clearly conform better to the model, the discrepancy in exchange constants between the two methods is only about $5 \%$. In any event, the simple method I for estimating $\overleftarrow{k}$ directly from the time lag $T$ does not appear to be greatly in error, so long as secondary maxima in the dissolved oxygen are absent. Because the mean photosynthetic rate is more strongly dependent upon the amplitude $A_{1}$ or $A_{2}$ than upon the exchange constant $\bar{k}$ [c.f. (31), (33)], the values obtained by method I are quite close to those found with method II. The agreement between respiration rates determined by the two methods is about the same as for the exchange constants, being within a few percent for the Aare-Bern data, and differing by about $40 \%$ for the Aare-Brugg, Sept-72 and RheinRheinfelden, Feb-72 data.

The fact that the majority of the rivers studied here do not conform well to the model in all seasons may be first discussed in terms of the similarity of the rivers with the model. Observations made at Aare-Bern reflect a relatively undisturbed stretch of river smoothly receiving water and plankton primarily from Thunersee. All other points of observation are below river stretches more heavily disturbed not only by natural erosion phenomena but also by the various effects of a high density of population and industry. Some pecularities of the rivers shall be discussed individually before attempting to make generalizations from the data.

(1) Aare-Bern. Along its greater than 50 kilometer course between the Thunersee and Bern the flow of the Aare is unimpeded by either dams or power plants. On the basis of (i) overall agreement between the results of methods I and II, and (ii) analysis employing the coefficients of the 12-hour components, this river is judged to conform rather closely to the model, certainly much closer than the other rivers.

(2) Aare-Brugg. Between the Bielersee and Brugg there are some 9 hydroelectric power plants interrupting the flow of the Aare over a distance of about 100 kilometers, including 5 on the final 35-kilometer stretch between Olten and Brugg. It is our conjecture that daily periodic diversion of the flow between turbines and spillways is the primary source of the secondary maximum in dissolved oxygen (in the correlation function), which is found to occur at about 9.00 p.m. (geographic time) for the Jan-72 data (c.f. Figure 5).

Although the Sept-72 data do not exhibit a similar secondary maximum, a significant discrepancy ( $40 \%$ ) in exchange constants calculated by methods I and II indicates the presence of additional (non-random) sources of periodicity in the data, besides just sunlight-induced photosynthesis.

The mean photosynthesis rate on this section of the Aare is smaller by a factor of 
Table 1. Pertinent River Data Obtained by Method I.

Tabelle 1. Mit der Methode I gewonnene Flussdaten.

\begin{tabular}{|c|c|c|c|c|c|c|c|c|c|c|c|}
\hline River & Station & Month & $\begin{array}{l}\text { Temp } \\
{ }^{\circ} \mathrm{C}\end{array}$ & $\begin{array}{l}\mathrm{O}_{\mathrm{eq}} \\
\mathrm{mg} / 1\end{array}$ & $\begin{array}{l}\overline{\mathrm{O}} \\
\mathrm{mg} / 1\end{array}$ & $\begin{array}{l}\mathrm{A}_{1} \\
\mathrm{mg} / 1\end{array}$ & $\begin{array}{l}T \\
h\end{array}$ & $\begin{array}{l}\overleftarrow{k} \\
\mathrm{~h}^{-1}\end{array}$ & $\begin{array}{l}0.25(1-R) \alpha I_{0} \\
\mathrm{mg} / \mathrm{l} \mathrm{h}\end{array}$ & $\begin{array}{l}\beta \\
\mathrm{mg} / 1 \mathrm{~h}\end{array}$ & $\begin{array}{l}\overleftarrow{k} \mathrm{O}_{\mathrm{eq}} \\
\mathrm{mg} / \mathrm{l} \mathrm{h}\end{array}$ \\
\hline Aare & Bern & $\operatorname{Jan} 74$ & 5 & 12.23 & 10.82 & 0.228 & 2.40 & 0.360 & 0.28 & 0.79 & 4.40 \\
\hline Aare & Bern & Mar 74 & 6 & 11.92 & 11.77 & 0.421 & 2.20 & 0.403 & 0.56 & 0.62 & 4.80 \\
\hline Aare* & Brugg* & Jan $72 *$ & $4.4^{*}$ & $12.36^{*}$ & $10.36 *$ & $0.0095^{*}$ & $0.60 *$ & $1.65^{*}$ & $0.04 *$ & $3.34^{*}$ & $20.39^{*}$ \\
\hline Aare & Brugg & Sep 72 & 15.2 & 9.60 & 8.25 & 0.056 & 3.20 & 0.236 & 0.06 & 0.37 & 2.27 \\
\hline Reuss* & Mellingen ${ }^{*}$ & $\operatorname{Jan} 72^{*}$ & $4.4^{*}$ & $12.36^{*}$ & $9.05^{*}$ & $0.029 *$ & $2.70^{*}$ & $0.307^{*}$ & $0.03 *$ & $1.05^{*}$ & $3.79^{*}$ \\
\hline Reuss & Mellingen & Jul 72 & 17.5 & 9.14 & 9.31 & 0.041 & 1.50 & 0.632 & 0.08 & -0.03 & 5.78 \\
\hline Limmat & Baden & Feb 72 & 5.1 & 12.20 & 9.12 & 0.124 & 1.28 & 0.752 & 0.27 & 2.59 & 9.17 \\
\hline Limmat* & Baden* & Jun $72^{*}$ & $15.2^{*}$ & $9.60^{*}$ & $9.08^{*}$ & $0.074^{*}$ & $12^{*}$ & * & * & * & * \\
\hline Rhein & Rheinfelden & Feb 72 & 4.9 & 12.26 & 10.89 & 0.093 & 1.30 & 0.739 & 0.20 & 1.22 & 9.06 \\
\hline Rhein & Rheinfelden & Jul 72 & 18.1 & 9.03 & 9.49 & 0.037 & 2.00 & 0.453 & 0.05 & -0.16 & 4.09 \\
\hline
\end{tabular}

* denotes a maximum in the cross-correlation function occurring later than $6.00 \mathrm{p}$. m., indicating that the model is not valid.

* bedeutet, dass das Maximum der Kreuzkorrelationsfunktion später als 6 Uhr nachmittags auftritt, was anzeigt, dass das Modell nicht gültig ist. 
Table 2. Pertinent River Data Obtained by Method II.

Tabelle 2. Mit der Methode II gewonnene Flussdaten.

\begin{tabular}{|c|c|c|c|c|c|c|c|}
\hline River & Station & Month & $\begin{array}{l}A_{2} \\
\mathrm{mg} / 1\end{array}$ & $\begin{array}{l}\stackrel{\leftarrow}{k} \\
\mathrm{~h}^{-1}\end{array}$ & $\begin{array}{l}0.25(1-\dot{\vec{R}}) \propto I_{0} \\
\mathrm{mg} / \mathrm{l} \mathrm{h}\end{array}$ & $\begin{array}{l}\beta \\
\mathrm{mg} / \mathrm{lh}\end{array}$ & $\begin{array}{l}\stackrel{\leftarrow h}{\mathrm{O}_{\text {eq }}} \\
\mathrm{mg} / \mathrm{l} \mathrm{h}\end{array}$ \\
\hline Aare & Bern & Jan 74 & 0.222 & 0.376 & 0.28 & 0.81 & 4.60 \\
\hline Aare & Bern & Mar 74 & 0.422 & 0.386 & 0.54 & 0.60 & 4.60 \\
\hline Aare* & Brugg* & $\operatorname{Jan} 72^{*}$ & $0.0078^{*}$ & $0.120^{*}$ & $0.006^{*}$ & $0.25 *$ & $1.48^{*}$ \\
\hline Aare & Brugg & Sept 72 & 0.047 & 0.344 & 0.06 & 0.520 & 3.30 \\
\hline Reuss* & Mellingen* & Jan $72^{*}$ & * & $*$ & * & * & $*$ \\
\hline Reuss & Mellingen & Jul 72 & 0.041 & 0.505 & 0.06 & -0.02 & 4.61 \\
\hline Limmat & Baden & Feb 72 & 0.124 & 0.807 & 0.29 & 2.78 & 9.85 \\
\hline Limmat* & Baden & Jun 72 & $*$ & $*$ & $*$ & $*$ & $*$ \\
\hline Rhein & Rheinfelden & Feb 72 & 0.090 & 0.535 & 0.15 & 0.88 & 6.55 \\
\hline Rhein & Rheinfelden & Jul 72 & 0.037 & 0.461 & 0.06 & -0.15 & 4.16 \\
\hline
\end{tabular}

* denotes a maximum in the cross-correlation function occurring later than 6.00 p.m., indicating that the model is not valid.

* bedeutet, dass das Maximum der Kreuzkorrelationsfunktion später als 6 Uhr nachmittags auftritt, was anzeigt, dass das Modell nicht gültig ist. 
10 or more than that on the stretch above Bern. The extremely low photosynthesis rate observed in Jan-72 may be partly a consequence of exceptionally heavy fog or cloud cover, as the raw data themselves revealed unusually marked random variations in dissolved oxygen during that period. It is possible that the detection of a secondary maximum in the Jan-72 data, in contrast to the Sept-72 data, is simply a consequence of the much smaller contribution of photosynthesis in the former case. It is unknown whether the reduced photosynthesis rate on this lower stretch of the Aare is due to an insufficiency in number, kind, or physiology of the photosynthetic organisms, or failure of the light to reach the bottom.

Although the photosynthesis rate of the Aare monitored at Brugg is indeed much smaller that found upstream at Bern, the summer (Sept-72) value at Brugg is essentially the same as summer ( Jul-72) values observed for the Reuss at nearby Mellingen, and for the Rhein at Rheinfelden, which is somewhat farther downstream. Perhaps such low photosynthesis rates are typical of the larger, deeper streams in that area of northern Switzerland. It should be remarked that our conclusions regarding the relative magnitudes of photosynthesis rates are probably valid despite serious shortcomings of the model, since they depend strongly just on the amplitudes of the 24-hour periodic fluctuations in dissolved oxygen, but only weakly on the exchange rates and not at all on the average concentrations $\bar{O}$, which are the two quantities most seriously perturbed by spillway aeration, dilution with colder saturated ground water, etc.

(3) Reuss-Mellingen. At the time of the oxygen measurements in 1972 there were no dams along the 50 kilometer length of the Reuss between the Lake of Lucerne (Vierwaldstättersee) and Mellingen, though there was a power plant at BremgartenZufikon, some 10-12 kilometers upstream from Mellingen, operating exclusively from a side-canal through which only $30 \%$ of the total river flow was diverted. Using a flow rate of about $1 \mathrm{~m} / \mathrm{sec}$, the flow time from Bremgarten to Mellingen is estimated to be about $1.4-1.7$ oxygen exchange lifetimes $\left\langle\tau_{0} \equiv 1 / \bar{k}=(0.505)^{-1}=\right.$ $1.98 \mathrm{~h}$ ). Allowing for dilution of the effluent water from the power plant as it rejoins the main stream, it can be determined that any spurious increases in dissolved oxygen from the power plant will have been reduced to $5-7 \%$ of their initial values by the time the water reaches Mellingen. Thus, if the curious secondary maximum observed at 12 midnight in the (Mellingen) Jan-72 cross-correlation function were to be attributed to the power plant, then rather large daily modulation of the oxygen content of its effluent would be implied.

A second indication of peculiar behavior of the Reuss is the very small, negative respiration value obtained from the Jul-72 data. Basically, this circumstance arises from the rather large amount by which the average value $\bar{O}$ of the dissolved oxygen exceeds the equilibrium value $O_{\text {eq }}$ during the summer. The problem is that the 24hour fluctuations in the dissolved oxygen are simply too small to be compatible with an average photosynthesis rate large enough to keep the river saturated to that degree. The real question, then, is whether some factors are ignored by the model such that supersaturation is not explained in terms of photosynthesis or whether the supersaturation derives from some other not yet known factors. The possibility that the absolute calibration of the oxygen electrode was in significant error during July-72 can be dismissed. 
A final point in connection with the Reuss Jan-72 data is that a secondary maximum in $\mathrm{pH}$ was also observed to occur at roughly the same time as the secondary maximum in dissolved oxygen. Since it was found that $\mathrm{pH}$ maxima occurring in every case simultaneously with the primary dissolved oxygen maxima could be satisfactorily interpreted in terms of $\mathrm{CO}_{2}$ uptake during photosynthesis, it might be inferred that the secondary oxygen maximum must also arise from photosynthesis, perhaps in the holding-reservoir or canal above the power plant. However, direct intervention by human regulation would probably still be required to produce the oxygen maximum during night-time hours, regardless of the source of the oxygen. At present, we have no completely satisfactory potential explanation for the unusual phenomena exhibited by the Reuss.

(4). Limmat-Baden. Unfortunately, the measuring station at Baden is located immediately below a dam and its associated power plant. The influence of the dam is readily apparent in the June-72 cross-correlation function, which exhibits a single extremely asymmetric maximum at about 11.00 p.m., clearly invalidating the model. Even the Feb-72 data reveal a 'shoulder' on the oxygen maximum that is not quite resolved into a separate peak. Our current feeling is that these data defy analysis and are, therefore, hopeless. Relocation of the oxygen measuring station to the upstream side of the Baden hydroelectric facility might well yield meaningful and important data.

(5). Rhein-Rheinfelden. Unfortunately, here too the measuring station is located only a few hundred meters below a major dam and power plant, which in turn lies only 3 kilometers downstream from yet a second dam. The negative respiration rate found for the July-72 data is most likely an artifact associated with oxygen supersaturation resulting from rapidly submerging air-water mixtures to considerable depths at the base of the dam. As in the case of the Reuss, the possibility that the oxygen electrode reporting supersaturation is significantly in error also can be ruled out..

It should be noted that a rapid supersaturation of the water immediately before the electrode would not by itself be expected to greatly alter the time lag $T$ of the dissolved oxygen maxima, or even necessarily to greatly alter the amplitudes of the periodic oxygen fluctuations, despite a rather large change produced in the average value $\bar{O}$. Of course, periodic daily regulation of the flow between turbines and spillways would contribute a spurious component to the 24-hour periodicity in the dissolved oxygen. However, in this case we find no substantial evidence for such regulation, in contrast to the Limmat-Baden example. Thus, it is probable that the exchange constants $\overleftarrow{k}$ and photosynthesis rates obtained for the Rhein-Rheinfelden data are, in fact, fairly representative of a particular stretch of river above the two dams, even though the corresponding respiration rates are unreliable.

In sunmary, our initial survey has turned up only one exemplary 'river', the Aare-Bern, and has revealed inexplicably peculiar behavior of a second 'river', the Reuss-Mellingen, which was originally expected to be also exemplary. The remaining 'rivers', that is, Aare-Brugg, Limmat-Baden, and Rhein-Rheinfelden, are all somewhat unsuitable because their measuring stations are located immediately below 
dams, which is a feature of the sampling strategy that should be rectified in future experiments by relocating the oxygen monitor stations to the upstream sides of any hydroelectric facilities. Despite these difficulties we have learned several things about our unsuitable rivers:

(i) The supersaturation in summer of the Reuss at Mellingen and the Rhein at Rheinfelden cannot be ascribed by the model primarily to photosynthetic production. Especially for the Reuss, it is difficult to see how such a marked supersaturation could arise by any means.

(ii) The photosynthesis rates on the lower river sections (Brugg, Mellingen and Rheinfelden) are significantly smaller than those of the Aare at Bern.

(iii) The exchange constants $\bar{k}$ found for the summer Aare-Brugg and ReussMellingen data, and also for the summer and winter Rhein-Rheinfelden data, are roughly of the same magnitude as those found for the Aare at Bern, indicating that exchange rates are probably comparable for all these rivers. Certainly, the Brugg, Mellingen and Rheinfelden data provide no evidence for a markedly reduced exchange rate associated with the somewhat greater size and depth of the streams in that area.

The results obtained here for the exchange constants may be compared with those obtained by the direct tracer method on somewhat smaller, more slowly moving streams in the southeastern U.S. [14]. The South River (50-100 cubic ft/sec) exhibited rate constants from 0.14 to $0.25 \mathrm{~h}^{-1}$, and 0.16 to $0.28 \mathrm{~h}^{-1}$ over one 8 -hour stretch, while the Patuxent exhibited values in the range 0.09 to 0.15 and 0.12 to 0.15 over a 12-14-hour stretch, while the much larger Chattahoochee $(1,000 \mathrm{cubic} \mathrm{ft} / \mathrm{sec})$ exhibited much lower exchange rates from 0.01 to $0.04 \mathrm{~h}^{-1}$. The Flint River $(10-20$ cubic $\mathrm{ft} / \mathrm{sec}$ ) manifested unusually large variations in exchange constant from one point to another, with values in the range 0.17 to $12.4 \mathrm{~h}^{-1}$ observed. The somewhat larger average values of the exchange constants obtained for the Swiss rivers in this study are undoubtedly a consequence of their rather higher velocities $(\gtrsim 1 \mathrm{~m} / \mathrm{sec})$ in comparison with the American streams ( $\lesssim 0.5 \mathrm{~m} / \mathrm{sec})$.

The maximum rate of photosynthesis $(1-\bar{R}) \propto I_{0}$ occurring at geographic noon is just 4 times the average (over all times) photosynthesis rate listed in Tables 1 and 2. By comparison with the final column in Tables 1 and 2 wherein the invasion rate of oxygen from the atmosphere $\overrightarrow{k O}_{A}=\overleftarrow{k O}_{\mathrm{eq}}$ is compiled, it can be seen that the maximum photosynthesis rate of the Aare at Bern was about one fourth of the atmospheric invasion rate in January 1974, and about a half the atmospheric invasion rate in March 1974. For heavily polluted, but photosynthetically active rivers, the desirability of modulating the BOD load to parallel the light intensity suggests itself as a means to avoid fatally low (for fish) oxygen levels during the night and early dawn.

The only trustworthy respiration rates are those for the Aare at Bern, although values obtained by method II for the other rivers, excepting Limmat-Baden, may be indicative of lower limits for their respiration rates, if it can be assumed that the predominant effect of the dams is to increase the average values $\bar{O}$ (immediately below the dams) over the values characteristic of the native rivers. 


\section{7. $\mathrm{pH}, \mathrm{CO}_{2}$, and Photosynthesis}

It was generally observed that periodic maxima in $\mathrm{pH}$, presumably associated with $\mathrm{CO}_{2}$ depletion, occurred nearly simultaneously with periodic maxima in the dissolved oxygen. The important questions are (i) whether an analysis of the $\mathrm{CO}_{2}$ dynamics, similar to that developed above for dissolved oxygen, can be applied, and (ii) whether the ratio of carbonate molecules consumed to oxygen molecules produced has approximately the value unity expected for photosynthesis. It will be seen in the ensuing development that, owing to the ionization equilibria in which it participates, the exchange dynamics of $\mathrm{CO}_{2}$ is somewhat more complex than the simple situation prevailing for oxygen. Nonetheless, in favorable cases (e.g., Aare-Bern), the analysis can be carried out almost exactly as before.

The pertinent reactions are:

$$
\begin{aligned}
& \mathrm{CO}_{2}(\mathrm{~g})=\mathrm{CO}_{2}(\mathrm{aq}) ; \mathrm{K}_{\mathrm{H}} \\
& \mathrm{CO}_{2}(\mathrm{aq})+\mathrm{H}_{2} \mathrm{O}=\mathrm{H}_{2} \mathrm{CO}_{3} ; \mathrm{K}_{\mathrm{H}_{2} \mathrm{CO}_{3}} \\
& \mathrm{H}_{2} \mathrm{CO}_{3}=\mathrm{H}^{+}+\mathrm{HCO}_{3}^{-} ; \mathrm{K}_{1} \\
& \mathrm{HCO}_{3}^{-}=\mathrm{H}^{+}+\mathrm{CO}_{3}^{-} ; \mathrm{K}_{2}
\end{aligned}
$$

In addition, a composite equilibrium constant for $\left[\mathrm{H}_{2} \mathrm{CO}_{3}^{*}\right] \equiv\left[\mathrm{CO}_{2}(\mathrm{aq})\right]+\left[\mathrm{H}_{2} \mathrm{CO}_{3}\right]$ may also be introduced for the 'reaction'

$$
\mathrm{H}_{2} \mathrm{CO}_{3}^{*}=\mathrm{H}^{+} \mathrm{HCO}_{3}^{-} ; \mathrm{K}_{1} \equiv \frac{\mathrm{K}}{\left(1+1 / \mathrm{K}_{\mathrm{H}_{2} \mathrm{CO}_{3}}\right)} \text {. }
$$

The $\mathrm{pK}$ values for the appropriate constants at $5^{\circ} \mathrm{C}$ are tabulated by STUMm and MorGan [24], $\mathrm{pK}_{1}=6.517$ [25], $\mathrm{pK}_{2}=10.557$ [26], and are corrected for the prevailing ionic strength $\mathrm{I}=2 \times 10^{-3}$ using the relations

thus,

$$
\begin{aligned}
& \mathrm{pK}_{1}^{\prime}=\mathrm{pK}_{1}-\frac{0.5 \sqrt{\mathrm{I}}}{(1+1.4 \sqrt{\mathrm{I}})}=6.496 \\
& \mathrm{pK}_{2}^{\prime}=\mathrm{pK}_{2}-\frac{2.0 \sqrt{\mathrm{I}}}{(1+1.4 \sqrt{\mathrm{I}})}=10.473
\end{aligned}
$$

$$
\begin{aligned}
& \mathrm{K}_{1}^{\prime}=3.192 \times 10^{-7} M^{-1} \\
& \mathrm{~K}_{2}^{\prime}=3.365 \times 10^{-11} M^{-1}
\end{aligned}
$$

A formula relating the total carbonate concentration in solution $C_{T} \equiv\left(\mathrm{CO}_{2}(\mathrm{aq})\right]+$ $\left[\mathrm{H}_{2} \mathrm{CO}_{3}\right]+\left[\mathrm{HCO}_{3}^{-}\right]+\left[\mathrm{CO}_{3}^{-}\right]$to the alkalinity $[\mathrm{Alk}]$ (about $1.0-1.5 \times 10^{-3}$ ) (for these Swiss Rivers) and the hydrogen-ion concentration is given by STUMM and Morgan [24] as:

$$
C_{T}=\left([\mathrm{Alk}]-\left[\mathrm{OH}^{-}\right]+\left[\mathrm{H}^{+}\right]\right) /\left(\alpha_{1}+2 \alpha_{2}\right) \cong[\mathrm{Alk}] /\left(\alpha_{1}+2 \alpha_{2}\right)
$$

for the $\mathrm{pH}$ 's of these rivers. The quantities $\alpha_{1}$ and $\alpha_{2}$ are defined by

$$
\begin{aligned}
& \alpha_{1} \equiv\left(\frac{\left[\mathrm{H}^{+}\right]}{\mathrm{K}_{1}^{\prime}}+1+\frac{\mathrm{K}_{2}^{\prime}}{\left[\mathrm{H}^{+}\right]}\right)^{-1} \\
& \alpha_{2} \equiv\left(\frac{\left[\mathrm{H}^{+}\right]^{2}}{\mathrm{~K}_{2}^{\prime} \mathrm{K}_{1}^{\prime}}+\frac{\left[\mathrm{H}^{+}\right]}{\mathrm{K}_{2}^{\prime}}+1\right)^{-1}
\end{aligned}
$$


and are, unfortunately, rather strongly and even non-linearly dependent upon $\left[\mathrm{H}^{+}\right]$ over the $\mathrm{pH}$ range of interest. The fraction $f_{0}$ of total carbonate present as $\mathrm{CO}_{2}(\mathrm{aq})$, which is the only species capable of exchanging directly with the air, is

$$
\left.f_{0} \equiv \frac{\left[\mathrm{CO}_{2}\right.}{C_{T^{r}}} \frac{(\mathrm{aq})]}{-1}=\frac{\mathrm{K}_{1}^{\prime}}{\left[\mathrm{H}^{+}\right]}+\frac{\mathrm{K}_{1}^{\prime} \mathrm{K}_{2}^{\prime}}{\left[\mathrm{H}^{+}\right]^{2}}\right)^{-1}
$$

and is also rather strongly and somewhat non-linearly dependent upon $\left[\mathrm{H}^{+}\right]$over the $\mathrm{pH}$ range of interest.

The dynamical equation for $C_{T}$, analagous to equation 1 for $\mathrm{O}_{2}$, may be written as

$$
\frac{\partial C_{T}}{\partial t}=-\hat{k}_{C} f_{0} C_{T}+\vec{k} C_{A}-\alpha^{\prime} I(t)+\beta^{\prime},
$$

wherein $\overleftarrow{k}_{C}$ is the exchange constant appropriate for $\mathrm{CO}_{2}(\mathrm{aq})$. It has been implicitly assumed that (i) carbonate uptake following light absorption occurs in a time sufficiently short sompared to both the atmospheric exchange time and the principal sunlight period, that its idealization as an instantaneous process in (41) is justified, and (ii) equilibration among carbonate species also occurs sufficiently rapidly compared to atmospheric exchange and sunlight oscillation, that use of the equilibrium fraction $f_{0}$ of total carbonate in the outgassing term $\overleftarrow{k}_{C} f_{0} C_{T}$ is justified.

The principal difficulty stems from the fact that a change in $C_{T}$, as effected by photosynthesis or reaeration, results in, or is coupled to, a change in $\left[\mathrm{H}^{+}\right]$through $(40-42)$. These $\left[\mathrm{H}^{+}\right]$changes in turn produce significant changes in the value of $f_{0}$ in (43), which may be thought of as a modulation of the effective constant for gas exchange of $C_{T}$. The magnitude of such changes can be estimated from the maximum $\mathrm{pH}=8.6$ and minimum $\mathrm{pH}=7.8$ observed for a particular clear day in a stretch of similar clear days of the March-74 Aare-Bern record. Employing the constants of (38) and (39) in (43), there results

$$
\begin{aligned}
& \mathrm{pH} 8.6: f_{0}=7.705 \times 10^{-3} \\
& \mathrm{pH} 7.8: \digamma_{0}=4.721 \times 10^{-2}
\end{aligned}
$$

The corresponding values of $C_{T}$ at these $\mathrm{pH}^{\prime}$ s are readily determined from (40), using an alkalinity of $1.5 \times 10^{-3}$ (close to observed values for the Aare at Thun), thus

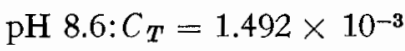

$$
\begin{aligned}
& \dot{\mathrm{pH}} 7.8: C_{T}=1.571 \times 10^{-3}
\end{aligned}
$$

Evidently, a change in $C_{T}$ amounting to only about $7 \%$ of its total causes the $\left[\mathrm{H}^{+}\right]$ concentration to change by a factor of $5(\Delta \mathrm{pH})=0.7)$, which results in a change in $f_{0}$ by about a factor of 6 . Thus, the effective exchange constant $\overleftarrow{k}_{C} f_{0}$, which appears in the dynamical equation (44) for $C_{T}$, is not a constant at all, but falls off dramatically as $C_{T}$ declines, and vice-versa, as indicated in Figure 6 . The nearly linear nature of the relation between $f_{0}$ and $C_{T}$ inspires hope that atmospheric exchange might still be treated as a linear process, as will be shown to be the case below. 


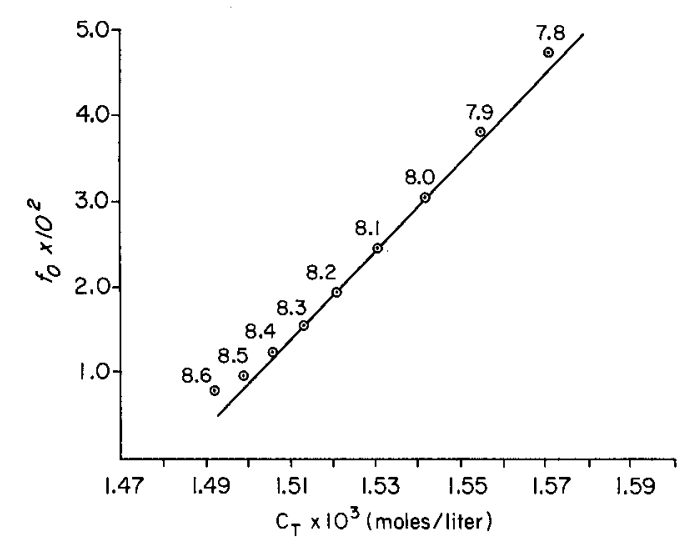

After expressing each time-dependent quantity as a sum of its stationary average value and a fluctuating part

$$
\begin{gathered}
C_{T}=\bar{C}_{T}+\Delta C_{T}(t) \\
I(t)=\bar{I}+\Delta I(t) \\
f_{0}=\bar{f}_{0}+\Delta f_{0}(t)
\end{gathered}
$$

substituting into (44), and separating stationary and time-dependent parts, there results

$$
\bar{C}_{T}=C_{T}^{\mathrm{eq}}-\frac{\alpha^{\prime} I}{\bar{k}_{C} f_{0}}+\frac{\beta^{\prime}}{\bar{k}_{C} f_{0}}
$$

where $C_{T}^{\text {eq }}$ is the equilibrium total carbonate at the temperature and alkalinity in question, and

$$
\frac{\partial \Delta C_{T}(t)}{\partial t}=-\bar{k}_{C}\left\{\bar{f}_{0} \Delta C_{T}(t)+\bar{C}_{T} \Delta f_{0}(t)+\Delta C_{T}(t) \Delta f_{0}(t)\right\}-\alpha^{\prime} \Delta I(t) .
$$

Since $\bar{C}_{T} \gg \Delta C_{T}$, the last term in braces may be neglected against the second. The quantity $\Delta f_{0} \equiv f_{0}(t)-f_{0}$ is evidently (c.f. Figure 6) nearly proportional to $\Delta C_{T}(t) \equiv$ 
$C_{T}(t)-\bar{C}_{T}$. Indeed, its power series is given by

$$
\Delta f_{0}=\left(\frac{\partial f_{0}}{\partial C_{T}}\right)_{a v} \Delta C_{T}+1 / 2\left(\frac{\partial^{2} f_{0}}{\partial C_{T}^{2}}\right)_{a v}\left(\Delta C_{T}\right)^{2}+\cdots
$$

wherein the coefficients are to be evaluated at the average values of all parameters. The coefficients have been numerically evaluated at $\mathrm{pH} 8.05$ (close to the average value), using the expressions

$$
\begin{gathered}
\left(\frac{\partial f_{0}}{\partial C_{T}}\right)_{a v}=\frac{d\left[\mathrm{H}^{+}\right]}{d C_{T}} \frac{\partial f_{0}}{\partial\left[\mathrm{H}^{+}\right]}=\left(\frac{d C_{T}}{d\left[\mathrm{H}^{+}\right]}\right)^{-1} \frac{\partial f_{0}}{\partial\left[\mathrm{H}^{+}\right]}=553.7 \\
\left(\frac{\partial^{2} f_{0}}{\partial C_{T}^{2}}\right)_{a v}=\left(\frac{d C_{T}}{d\left[\mathrm{H}^{+}\right]}\right)^{-2} \frac{\partial^{2} f_{0}}{\partial\left[\mathrm{H}^{+}\right]}-\left(\frac{d C_{T}}{d\left[\mathrm{H}^{+}\right]}\right)^{-3} \frac{\partial f_{0}}{\partial\left[\mathrm{H}^{+}\right]} \frac{d^{2} C_{T}}{d\left[\mathrm{H}^{+}\right]^{2}}=2.067 \times 10^{6}
\end{gathered}
$$

Since the maximum value of $\Delta C_{T}$ in which we are here interested is one-half the difference between $C_{T}$ values at $\mathrm{pH} 7.8$ and 8.6 , or about $4 \times 10^{-5} \mathrm{M}$, a comparison of the two terms in (47) at the maximum $\Delta C_{T}$ (i.e., at the end of the range) can be inferred from the appropriate expression

$$
\Delta t_{0}=2.21 \times 10^{-2}+1.65 \times 10^{-3}+\cdots
$$

from which it is readily concluded that the non-linear, or square, term in $\Delta C_{T}^{2}$ is negligible over the entire range of interest. Neglecting the second term in (47), then, one has finally

$$
\frac{\partial \Delta C_{T}(t)}{\partial t}=-\bar{k}_{C}\left\{\bar{f}_{\mathbf{0}}+\bar{C}_{\boldsymbol{T}}\left(\frac{\partial f_{0}}{\partial C_{T}}\right)_{a v}\right\} \Delta C_{T^{\prime}}(t)-\alpha^{\prime} \Delta I(t)
$$

in which the exchange rate is simply proportional to $\Delta C_{T}(t)$. From the relative magnitudes of $\bar{f}_{0}=2.706 \times 10^{-2}$ and $\bar{C}_{T}\left(\partial f_{0} / \partial C_{T}\right)_{a v}=8.505 \times 10^{-1}$, it is apparent that the predominant term in the exchange rate derives not from variations in $C_{T}$ directly, but from the changes induced in $f_{0}$ by $\mathrm{pH}$ changes associated with the variation in $C_{T}$. The effective exchange constant is now

$$
\overleftarrow{k}_{C}^{\prime}=\overleftarrow{k}\left\{\bar{f}_{0}+\bar{C}_{T}\left(\frac{\partial f_{0}}{\partial C_{T}}\right)_{a v}\right\}=0.877 \bar{k}_{C}
$$

where $\widetilde{k}_{C}$ is still the exchange constant appropriate to the species $\mathrm{CO}_{2}(\mathrm{aq})$.

Because (49) for the dynamics of evolution of the fluctuating $\Delta C_{T}(t)$ is formally identical (apart from the sign of the photosynthesis term) to (6) for $\Delta O(t)$, its solutions also have the same form, except for a change in sign of the response. In particular, for the 24-hour component the solution is

where now

$$
-\Delta C_{T}(t)=\mathrm{A} \cos (t-T),
$$

$$
\begin{gathered}
T=\frac{1}{\Omega} \tan ^{-1}\left(\frac{\Omega}{0.88 \bar{k}_{C}}\right) \\
A=\frac{\alpha^{\prime} I_{0} / 2}{\left(\Omega^{2}+\left(0.88{ }^{(} C\right)^{2}\right)^{1 / 2}} .
\end{gathered}
$$


Indeed, the entire development for the sunlight-dissolved oxygen cross-correlation function can be readily transferred to $\Delta C_{T}$ with similar obvious results.

Although we have not yet actually digitized a $\mathrm{pH}$ curve, translated it to $C_{T}$ using the measured alkalinity, and computed the sunlight-dissolved carbonate cross-correlation function, it was found possible to achieve reasonably precise estimates of the time lag and magnitude of the trough-to-crest variation in $\mathrm{pH}$ during a stretch of similar sunny days on the Aare-Bern, March-74 record. The time lag for the $\mathrm{pH}$ maxima was about 25 minutes longer than the 2.20 hour time lag of the dissolved oxygen, from which it can be calculated using (52) that $\bar{k}_{C}=0.365$, in contrast with the corresponding value $\overleftarrow{k}=0.403$ for oxygen. From these numbers it may be inferred that $\mathrm{CO}_{2}(\mathrm{aq})$ exchanges, or outgasses, at a rate about $9 \%$ slower than the dissolved oxygen. The effective exchange constant $(0.88) \overleftarrow{k}_{C}$ for total carbonate is about $20 \%$ lower than that for dissolved oxygen.

Corresponding to the variation in $\mathrm{pH}$ from 7.8 to 8.6 , the dissolved oxygen changed by about $2.7 \mathrm{mg} / \mathrm{ml}$ during the same day, equivalent to about $8.4 \times 10^{-5}$ moles $\mathrm{O}_{2} / 1$. As noted above, the total carbonate calculated from these $\mathrm{pH}$ 's changed from $1.571 \times 10^{-3}$ to $1.492 \times 10^{-3}$, a change of $7.9 \times 10^{-5}$ moles carbonate 1 . The ratio $\alpha / \alpha^{\prime}$ of photosynthetic coefficients (expressed in molar units), is evidently just

$$
\frac{\alpha}{\alpha^{\prime}}=\frac{\left(\Omega^{2}+\overleftarrow{k^{2}}\right)^{1 / 2}\left(8.4 \times 10^{-5}\right)}{\left(\Omega^{2}+\left(.88 \overleftarrow{k}_{C}\right)^{2}\right)^{1 / 2}\left(7.9 \times 10^{-5}\right)}=1.2,
$$

wich is satisfactorily close to 1.0 considering that the inherent accuracy of our crude estimation procedure, simply noting the maximum and minimum $\mathrm{pH}$ and oxygen values for a particular day in the chart record, cannot be all that good.

The fact that analysis of $\mathrm{pH}$ variations gives results, which are completely consistent with those obtained above by analysis of dissolved oxygen variations, constitutes a considerable argument for the validity of our model, in which sunlightinduced photosynthesis is the predominant source of the 24-hour fluctuations in either $\mathrm{pH}$ or dissolved oxygen. Furthermore, the possibility that estimates of gas exchange, photosynthesis, and respiration dynamics in rivers can be effected solely from $\mathrm{pH}$ measurements together with measured temperatures and alkalinities is now apparent. However, it should be cautioned that it must be verified in every case that the change in $f_{0}$ with $C_{T}$ is nearly linear. Similarly, the value of the parameter $\bar{f}_{0}+\left(\partial f_{0} / \partial C_{T}\right)_{a y} \bar{C}_{T}$ appearing in (49) and (50) will have to be determined anew in each case. Finally, very accurate reading of the $\mathrm{pH}$ will have to be made to prevent sizeable errors, mainly because the $\mathrm{pH}$ electrode monitors the logarithm of the hydrogen-ion concentration, rather than the concentration directly, as is the case for the oxygen electrode.

The most desirable procedure is to run analyses on both oxygen and $\mathrm{pH}$, and by comparison of the results to judge the validity of the model, in particular to determine whether large non-photosynthetic periodic perturbations of oxygen and $\mathrm{pH}$ are occurring in the river. 


\section{Refinement of the Model}

Theoretical consequences have already been worked out [21] for a number of refinements to the model including:

(i)) effect of variation in dissolved oxygen at the origin of the river

(ii variation of the photosynthetic rate coefficient $\alpha$ and the respiration rate $\beta$ with position along the river

(iii) inclusion of longitudinal diffusion in the equation of motion for oxygen

(iv) 24-hour periodic injection of substrate at some point

(v) variation in exchange constant $k$ with position along the river. Not surprisingly the treatment of such refinements has required considerably more formidable mathematics than that employed here, and for the most part, the results do not lend themselves readily to simple interpretation of actual data from a single electrode. Even though proper accounting for certain refinements indicates that the experimental quantities, such as time delay, amplitude, and average value, are rather more complicated expressions than those employed here, it still appears that the simple interpretations made above will faithfully reflect the trend of any long term (i.e., year to year) changes in photosynthesis rate, or respiration rate. Thus, the simple model provides at the very least a reliable monitor of water quality changes in any given stream.

\section{Summary}

The oxygen exchange constant, photosynthesis rate, and rate of respiration for each of several Swiss rivers were determined from the continuous data record of a single oxygen electrode. Direct computation of the cross-correlation function between an assumed ideal sunlight curve and the dissolved oxygen concentration effectively selected out the principal 24-hour component of the dissolved oxygen response, whose time lag and amplitude then permitted calculation of the oxygen exchange constant and photosynthesis rate. Values obtained for the Aare at Bern are: $0.38 \mathrm{~h}^{-\mathbf{1}}$ for the exchange constant; $0.6-0.8 \mathrm{mg} /(1 \mathrm{~h})$ for the respiration rate; and $0.28 \mathrm{mg} /(1 \mathrm{~h})$ for the mean photosynthesis rate in January, increasing to $0.54 \mathrm{mg} /(\mathrm{l} \mathrm{h})$ in March.

An extension of this same technique to the dynamics of total carbonate concentration, as monitored by a continuously recording $\mathrm{pH}$ electrode, was also effected. The exchange constant for dissolved, but not hydrated or ionized, $\mathrm{CO}_{2}$ was found to be about 0.91 times that for dissolved oxygen, and the photosynthesis yield ratio (oxygen molecules produced/carbonate molecules consumed) was found to be about 1.2 for the Aare at Bern.

\section{ZUSAMMENFASSUNG}

Es wird eine Methode zur Bestimmung der Raten für Sauerstoffeintrag, Photosynthese und Atmung in einem Fluss vorgeschlagen, die sich auf die Auswertung der kontinuierlichen Sauerstoffmessung durch eine Elektrode stützt. Die Methode basiert auf einem einfachen Modell, das die Dynamik des Sauerstoffhaushaltes unter Einbezug der Wirkung des Sonnenlichtes für ideale, gleichförmige Flüsse beschreibt. Von Wolken und atmosphärischem Staub bedingte zufällige Schwankungen der Lichtintensität werden durch Berechnung der Kreuzkorrelationsfunktion zwischen einer angenommenen idealen Sonnenlichtkurve und der im Fluss experimentell bestimm- 
ten Sauerstoffkurve eliminiert. Es wird gezeigt, wie die Zeitverzögerung und die Amplitude des gelösten Sauerstoffs als Antwort auf das periodische Sonnenlicht mit der Rate des Sauerstoffgasaustausches und der Photosynthese zusammenhängen. Ferner wird gezeigt, wie zusätzlich mit Hilfe der mittleren gelösten Sauerstoffkonzentration die Respirationsrate bestimmt werden kann. Die Anwendung dieser Methode auf die Sauerstoffdaten verschiedener Schweizer Flüsse wird eingehend dargestellt und diskutiert.

Eine Erweiterung der gleichen Methode auf das kompliziertere Problem des Kohlendioxidhaushaltes wird ebenfalls entwickelt. Dadurch werden die Raten für $\mathrm{CO}_{2}$-Gasaustausch, Photosynthese und Atmung aus der kontinuierlichen Messung einer einzelnen pH-Elektrode sowie aus der Alkalinität des Flusses bestimmt. Fur die Aare (Bern) im März 1974 ergab sich, dass die Austauschrate für $\mathrm{CO}_{2}$ etwa $9 \%$ kleiner war als diejenige für $\mathrm{O}_{2}$, und das Verhältnis von photosynthetisch produziertem $\mathrm{O}_{2}$ zu konsumiertem $\mathrm{CO}_{2}$ betrug etwa 1.2 .

\section{RESSUME}

Une nouvelle méthode basée sur l'évaluation de mensurations d'oxygène continues par électrode est proposée pour la détermination des paramètres suivants : le taux d'apport en oxygène, la photosynthèse et la respiration du cours d'eau. La méthode s'appuie sur un modèle simple représentant la dynamique du bilan d'oxygène, y compris la réaction à la lumière solaire, dans des cours d'eau idéals et uniformes. Des fluctuations occasionnelles dans l'intensité de la lumière solaire, dues aux nuages et à la poussière atmosphérique, peuvent être éliminées par computation directe de la fonction de correlation avec retard entre une courbe de lumière solaire idéale présumée et la courbe d'oxygène dissous tirée d'observations expérimentales. La correlation entre le décalage de temps et l'amplitude de l'oxygène dissous comme réaction à la lumière solaire intermittente d'une part et la constante d'échange et le taux de la photosynthèse d'autre part est démontrée. En plus, la méthode illustre comment le taux de respiration peut être déterminé à l'aide de la concentration moyenne d'oxygène dissous. L'application de cette méthode à des valeurs d'oxygène dissous dans de divers cours d'eau suisses est présentée et discntée en détail.

La même méthode est aussi étendue au problème plus complexe du bilan du bi-oxyde de carbone. Elle permet de déterminer la constante d'échange en $\mathrm{CO}_{2}$, la photosynthèse et la respiration à l'aide de l'enregistrement continu d'une seule électrode pH et l'alcalinité du cours d'eau. Une étude dans l'Aar (Berne) en mars 1974 a révélé que le taux d'échange $\mathrm{CO}_{2}$ était de $9 \%$ inférieur au taux d'oxygène; le rapport entre l'oxygène produit photosynthétiquement et le $\mathrm{CO}_{2}$ consommé s'établit autour de 1,2 .

\section{ACKNOWLEDGEMENTS}

The authors would like to express their thanks to 'Prof. W. Stumm, Prof. H. Ambühl, Dr. R. Koblet, Mr. P. Erni and Mr. J. Wetzel for their interest and help. The help of Mr. M. Fischer and his collaborators at the Swiss Federal Water Resource Bureau in providing the data and further important informations deserve our special gratitude.

\section{REFERENCES}

[1] H. W. Streeter and E. B. Phelps, A Study of the Pollution and Natural Purification of the Ohio River. III. Factors Concerned in the Phenomena of Oxidation and Reaeration, Pub. Health Bull. No. 146, US Pub. Health Serv. (Washington, D.C. (1925).

[2] W. E. Doвbins, The Nature of Oxygen Transfer Coefficient in Aeration Systems Part 2-1 of Biological Treatment of Sewage and Industrial Wastes, by McCabe and Eckenfelder (Rheinhold, New York, N.Y., 1956).

[3] W. E. Dobbins, BOD and Oxygen Relationships in Stveams, J. Sanit. Eng. Div., Proc. ASCE 90, SA3, 53 (1964).

[4] W. E. Dobrins, closure of BOD and Oxygen Relationships in Streams, J. Sanit. Eng. Div., Proc. ASCE 91, SA5, 49 (1965). 
[5] D. J. O'Connor and W. E. Dobbins, Mechanism of Reaeration in Natural Streams, Transactions of ASCE 123, 641 (1956).

[6] D. J. O'ConnoR, The BOD Assimilation Capacity of the Lower James River, Virginia, Report to the State Water Control Board, Commonwealth of Virginia (1960).

[7] M. A. Churchill, H. L. Elmore and R. A. Buckingham, Prediction of Stream Reaeration Rates, J. Sanit. Eng. Div., Proc. ASCE 88, SA4, 1 (1962).

[8] H. N. Korvo and A. J. Korvo, Optimal Estimation of Polluted Stream Variables, 3rd IFAC Symposium on Identification and System Parameter Estimation, 1973 (North-HollandAmerican Elsevier).

[9] G. M. Hornberger and M. G. Kellex, A New Method for Estimating Productivity in Standing Waters Using Free Oxygen Measurements, Water Resources Bull. 10, 265 (1974).

[10] D. J. O'Connor, The Temporal and Spatial Distribution of Dissolved Oxygen in Streams, Water Resources Research 3, 65 (1967).

[11] G. G. Vinberg, Pervichnaya Produktsia Voedoemov, Isdatelstvo Akademii Nauk, Belorusskaya, S.S.R. Minsk. Transl. from U.S. Atomic Energy Comm., AEC-tr-5692, 2 Vol., 601 pp. (1960).

[12] E. C. Tsivoglou, Tracer Measurement of Stream Reaeration, Federal Water Pollution Control Administration, U.S. Department of the Interior (Washington, D.C. June 1967).

[13] E. C. Tsivoglou, R. L. O'Connell, C. M. Walter, P. J. Godsil and G. S. Logsdon, Tracer Measurements of Atmospheric Reaertion. I. Laboratory Studies, J. Water Pollut. Contr. Fed. 37,1343 (1965).

[14] E. C. Tsivoglou, J. R. Wallace, R. J. Velten and L. A. Neal, Work reported in the Symposium on Direct Tracer Measurement of the Reaeration Capacity of Streams and Estuaries, July 7-8, 1970; co-sponsors - Georgia Institute of Technology and U.S. Environmental Protection Agency, Water Pollution Control Research Series 16050 for 01/72.

[15] J. R. Longtin, Radiological Safety, in: Symposium on Direct Tracer Measurement of the Reaeration Capacity of Streams and Estuaries, July 7-8, 1970; co-sponsors - Georgia Institute of Technology and U.S. Environmental Protection Agency, Water Pollution Control Research Series 16050 for $01 / 72$, pp. 19-20.

[16] E. C. Tsivoglou, Relative Gas Transter Characteristics of Krypton and Oxygen, in: Symposium on Divect Tracer Measurement of the Reaeration Capacity of Streams and Estuaries, July 7-8, 1970; co-sponsors - Georgia Institute of Technology and U.S. Environmental Protection Agency, Water Pollution Control Research Series 16050 for 01/72, pp. 139.

[17] J. R. WALLACE, see reference [14], p. 91.

[18] A. Einstein, Schallausbreitung in teilweise dissoziierten Gasen, Sitzber. Preuss. Akad. Wiss., Physik. Math. Kl., p. 380 (1920).

[19] A. EICHENBERGER, private communication.

[20] K. Wuhrmann, Grundlagen für die Dimensionierung der Belüftung bei Belebtschlammanlagen, Schweiz. Z. Hydrol. 26, 310 (1964).

[21] R. Gächter, Die Bestimmung der Tagesraten der planktischen Primärproduktion - Modelle und In-situ-Messungen, Schweiz. Z. Hydrol. 34, 211 (1972).

[22] P. VALKo, personal communication.

[23] M. FISCHER, Meßstationen für die kontinuierliche Überwachung der Wassergüte, Wasser- und Energiewirtschaft 64, 215 (1972).

[24] W. Stumm and J. J. Morgan, Aquatic Chemistry (John Wiley \& Sons, Inc. N.Y. 1970).

[25] H. S. HARNED and R. Davis, Jr., The Ionization Constant of Carbonic Acid in Water and the Solubility of Carbon Dioxide in Water and Aqueous Salt Solutions from 0 to 50 $0^{\circ}$ J. Amer. Chem. Soc. 65, 2030 (1943).

[26] H. S. Harned and S. R. Scholes, Jr., The Ionization Constant of $\mathrm{HCO}_{3}^{-}$from 0 to $50^{\circ}$, J. Amer. Chem. Soc. 63, 1706 (1941).

[27] J. M. SCHURR, unpublished calculations.

Adresses of the authors:

Dr. J. M. Schurr, University of Washington, Department of Chemistry, BG-10, Seattle, Washington, 98195, USA.

Dr. J. Ruchti, EAWAG, CH-8600 Dübendorf, Switzerland. 